\title{
Urbanized microbiota in infants, immune constitution and later risk of atopic diseases
}

\author{
Lehtimäki, Jenni; Thorsen, Jonathan; Rasmussen, Morten Arendt; Hjelmsø, Mathis ; Shah, Shiraz; \\ Mortensen, Martin S.; Trivedi, Urvish; Vestergaard, Gisle Alberg; Bønnelykke, Klaus; Chawes, Bo Lund \\ Total number of authors: \\ 14
}

Published in:

Journal of Allergy and Clinical Immunology

Link to article, DOI:

10.1016/j.jaci.2020.12.621

Publication date:

2021

Document Version

Peer reviewed version

Link back to DTU Orbit

Citation (APA):

Lehtimäki, J., Thorsen, J., Rasmussen, M. A., Hjelmsø, M., Shah, S., Mortensen, M. S., Trivedi, U., Vestergaard, G. A., Bønnelykke, K., Chawes, B. L., Brix, S., Sørensen, S. J., Bisgaard, H., \& Stokholm, J. (2021). Urbanized microbiota in infants, immune constitution and later risk of atopic diseases. Journal of Allergy and Clinical Immunology, 148(1), 234-243. https://doi.org/10.1016/j.jaci.2020.12.621

\section{General rights}

Copyright and moral rights for the publications made accessible in the public portal are retained by the authors and/or other copyright owners and it is a condition of accessing publications that users recognise and abide by the legal requirements associated with these rights.

- Users may download and print one copy of any publication from the public portal for the purpose of private study or research.

- You may not further distribute the material or use it for any profit-making activity or commercial gain

- You may freely distribute the URL identifying the publication in the public portal 


\section{Journal Pre-proof}

Urbanized microbiota in infants, immune constitution and later risk of atopic diseases

Jenni Lehtimäki, PhD, Jonathan Thorsen, MD, PhD, Morten Arendt Rasmussen, $\mathrm{PhD}$, Mathis Hjelms $\varnothing$, PhD, Shiraz Shah, PhD, Martin S. Mortensen, PhD, Urvish Trivedi, $\mathrm{PhD}$, Gisle Vestergaard, PhD, Klaus Bønnelykke, MD, PhD, Bo Lund Chawes, MD, $\mathrm{PhD}$, Susanne Brix, PhD, Søren J. Sørensen, PhD, Hans Bisgaard, MD, PhD, Jakob Stokholm, MD, PhD

PII: S0091-6749(20)32407-6

DOI: $\quad$ https://doi.org/10.1016/j.jaci.2020.12.621

Reference: YMAI 14899

To appear in: Journal of Allergy and Clinical Immunology

Received Date: 17 September 2020

Revised Date: 11 November 2020

Accepted Date: 8 December 2020

Please cite this article as: Lehtimäki J, Thorsen J, Rasmussen MA, Hjelmsø M, Shah S, Mortensen MS, Trivedi U, Vestergaard G, Bønnelykke K, Chawes BL, Brix S, Sørensen SJ, Bisgaard H, Stokholm J, Urbanized microbiota in infants, immune constitution and later risk of atopic diseases, Journal of Allergy and Clinical Immunology (2021), doi: https://doi.org/10.1016/j.jaci.2020.12.621.

This is a PDF file of an article that has undergone enhancements after acceptance, such as the addition of a cover page and metadata, and formatting for readability, but it is not yet the definitive version of record. This version will undergo additional copyediting, typesetting and review before it is published in its final form, but we are providing this version to give early visibility of the article. Please note that, during the production process, errors may be discovered which could affect the content, and all legal disclaimers that apply to the journal pertain.

(C) 2020 Published by Elsevier Inc. on behalf of the American Academy of Allergy, Asthma \& Immunology. 
1 URBANIZED MICROBIOTA IN INFANTS, IMMUNE CONSTITUTION AND LATER

2 RISK OF ATOPIC DISEASES

4 Jenni Lehtimäki ${ }^{1}$, PhD, Jonathan Thorsen ${ }^{1,2}$, MD, PhD, Morten Arendt Rasmussen ${ }^{1,3}$, PhD,

5 Mathis Hjelms $\emptyset^{1}$, PhD, Shiraz Shah ${ }^{1}$, PhD, Martin S. Mortensen ${ }^{4,5}$, PhD, Urvish Trivedi ${ }^{4}$,

6 PhD, Gisle Vestergaard ${ }^{4,6}$, PhD, Klaus Bønnelykke¹, MD, PhD, Bo Lund Chawes ${ }^{1}$ MD, PhD,

7 Susanne Brix ${ }^{7}$, PhD, Søren J. Sørensen" ${ }^{4}$ PhD, Hans Bisgaard*1, MD, PhD, Jakob Stokholm¹,

8 MD, PhD

91 COPSAC, Copenhagen Prospective Studies on Asthma in Childhood, Herlev and Gentofte

10 Hospital, University of Copenhagen, Ledreborg Alle 34, 2820, Gentofte, Denmark

$11{ }^{2}$ Novo Nordisk Foundation Center for Basic Metabolic Research, Faculty of Health and Medical

12 Sciences, University of Copenhagen, Blegdamsvej 3b, 2100, Copenhagen, Denmark

$13{ }^{3}$ Section of Chemometrics and Analytical Technologies, Department of Food Science, University

14 of Copenhagen, Rolighedsvej 30, 1958, Frederiksberg C, Denmark

$15{ }^{4}$ Section of Microbiology, Department of Biology, University of Copenhagen,

16 Universitetsparken 15, 2100, Copenhagen, Denmark

$17{ }^{5}$ Host-Microbiota Interactions Laboratory, Wellcome Sanger Institute, Wellcome Genome

18 Campus, Hinxton, UK

$19{ }^{6}$ Section for Bioinformatics, Department of Health Technology, Technical University of

20 Denmark, 2800 Lyngby, Denmark

$21{ }^{7}$ Department of Biotechnology and Biomedicine, Technical University of Denmark, Lyngby,

22 Denmark.

23 *Correspondence: Professor Hans Bisgaard, MD, DMSc, address: Ledreborg Alle 34, 2820,

24 Gentofte, Denmark, phone: +45 3867 7360, E-mail: bisgaard@copsac.com 
26 Conflict of interest: All authors declare no potential, perceived, or real conflict of interest

27 regarding the content of this manuscript. The funding agencies did not have any role in design

28 and conduct of the study; collection, management, and interpretation of the data; or

29 preparation, review, or approval of the manuscript. No pharmaceutical company was involved

30 in the study.

32 Source of Funding: All funding received by COPSAC is listed on www.copsac.com. The

33 Lundbeck Foundation (Grant no R16-A1694); The Ministry of Health (Grant no 903516);

34 Danish Council for Strategic Research (Grant no 0603-00280B) and The Capital Region

35 Research Foundation have provided core support to the COPSAC research center. Dr. Jonathan

36 Thorsen is supported by the BRIDGE - Translational Excellence Programme (bridge.ku.dk) at

37 the Faculty of Health and Medical Sciences, University of Copenhagen, funded by the Novo

38 Nordisk Foundation. Grant agreement no. NNF18SA0034956. 


\section{ABSTRACT}

41 Background Urbanization is linked with an increased burden of asthma and atopic traits. A

42 putative mechanism is insufficient exposure to beneficial microbes early in life leading to

43 immune dysregulation as previously shown for indoor microbial exposures.

44 Objective To investigate whether urbanization is associated with the microbiota composition

45 in the infants' body and early immune function, and whether these contribute to the later risk

46 of asthma and atopic traits.

47 Methods We studied the prospective COPSAC $_{2010}$ mother-child cohort of 700 children growing

48 up in areas with different degrees of urbanization. During their first year of life, airway and gut

49 microbiota as well as immune marker concentrations were defined. At six years of age, asthma

50 and atopic traits were diagnosed by pediatricians.

51 Results In adjusted analyses, the risk of asthma and aeroallergen sensitization were increased

52 in urban infants. The composition of especially airway, but also gut microbiota differed

53 between urban and rural infants. The living environment related structure of the airway

54 microbiota associated with immune mediator concentrations already at one month of age. An

55 urbanized structure of airway and gut microbiota associated with an increased risk of asthma

56 coherently during multiple time points, and also with the risks of eczema and sensitization.

57 Conclusion Our findings suggest that urbanization related changes in the infant microbiota

58 may elevate the risk of asthma and atopic traits, probably via crosstalk with the developing

59 immune system. The airways may facilitate this effect as they are open for colonization by

60 environmental, airborne microbes and serve as immune interface. 


\section{Key messages}

73 Capsule summary In a prospective cohort study, an urban living environment and urbanized

74 infant microbiota associated with increased risks of asthma, eczema and aeroallergen

75 sensitization at six years of age probably due to early immune dysregulation.

childhood

\section{Abbreviations}

$81 \quad \mathrm{aOR}=$ adjusted odds ratio

$82 \quad$ ANOVA $=$ Analysis of variance

$83 \mathrm{CCL}=(\mathrm{C}-\mathrm{C}$ motif $)$ chemokine ligand

$84 \quad \mathrm{CRP}=\mathrm{C}$-reactive protein

85 COPSAC $=$ Copenhagen Prospective Studies on Asthma in Childhood

$86 \mathrm{CXCL}=(\mathrm{C}-\mathrm{X}-\mathrm{C}$ motif $)$ chemokine ligand

$87 \quad \mathrm{IL}=$ Interleukin

$88 \quad \mathrm{INF}=$ Interferon

89 TGF = Transforming growth factor 
$90 \quad \mathrm{TNF}=$ Tumor necrosis factor

$91 \quad \mathrm{OR}=$ Odds ratio

$92 \quad$ PAM = Partitioning Around Medoids

$93 \quad$ PCA = Principal Component Analysis

$94 \quad \mathrm{PCoA}=$ Principal Coordinates Analysis

95 PERMANOVA = Permutational Multivariate Analysis of variance

96 RMSE $=$ Root Mean Squared Error

$97 \quad \operatorname{sig} \mathrm{E}=$ specific Immunoglobulin $\mathrm{E}$

98 SPT $=$ skin prick test

99 sPLS = Sparse Partial Least Squares 
101 Urban children tend to have a higher risk of developing asthma ${ }^{1,2}$ and atopic traits such as

102 allergic sensitization ${ }^{3}$, rhinitis ${ }^{4}$ and eczema ${ }^{5}$ than rural children. Several factors differ between

103 these populations including larger family size and increased exposure to animals in rural areas,

104 which may contribute to the difference in disease risk ${ }^{6-8}$. Also, the microbial exposures are

105 different between rural and urban areas, which has been shown for the composition of 106 outdoor, indoor and human microbiota ${ }^{9-12}$. These microbial differences may mediate the 107 protective effect of a rural environment, as demonstrated for farming-related indoor 108 microbiota, which has been repeatedly associated with asthma protection ${ }^{13-15}$, also in 109 experimental settings ${ }^{14,16,17}$.

110 Microbial exposures are especially important during infancy and early childhood, when the

111 constitution of the immune system is primed by extensive immune-microbiota crosstalk ${ }^{18,19}$.

112 Indeed, accumulating evidence shows that infant microbiota is altered prior to the

113 development of allergic sensitization, rhinitis ${ }^{20}$, eczema ${ }^{21}$ and/or asthma ${ }^{22-24}$, potentially

114 influencing this early crosstalk. A recent report suggested that growing up in farms can

115 support the maturation of infants' gut microbiota and thus reduce their risk of asthma when

116 compared to other rural children ${ }^{25}$. However, it remains unclear how constantly increasing

117 urbanization of our living environments influence on early immune-microbiota crosstalk and

118 later risk of disease.

119 To address the hypothesis that dissimilar microbiota between urban and rural infants

120 contribute to the development of their immune system and the later risk of disease, we utilized

121 longitudinal data from the Copenhagen Prospective Studies on Asthma in Childhood 2010

122 (COPSAC 2010) mother-child cohort. We defined the degree of urbanization in their living

123 environment during infancy and studied its associations with asthma and atopic traits at age

124 six years. We further investigated whether the early microbiota composition of airways and 
125 gut as well as the local airway and systemic immune function may convey associations

126 between living environment and disease.

\section{METHODS}

\section{Cohort}

129 Children in the COPSAC 2010 mother-child cohort $(\mathrm{n}=700)$ have been followed prospectively

130 since birth with numerous scheduled visits at a dedicated research unit. Comprehensive

131 descriptions of the cohort and the research approach are published ${ }^{26-28}$. The COPSAC

132 pediatricians were solely responsible for diagnosis and treatment of all respiratory, allergy and

133 skin-related symptoms.

\section{Definition of asthma and atopic traits}

135 Asthma by age 6 years was diagnosed prospectively based on a previously detailed

136 quantitative symptom algorithm ${ }^{26,29}$ (Online repository methods).

137 Eczema by age 6 years was diagnosed prospectively based on the criteria of Hanifin and $138 \mathrm{Rajka}^{30}$ requiring the presence of 3 of 4 major criteria and at least 3 of 23 minor criteria.

139 Allergic rhinitis at age 6 years was based on sensitization and clinical interviews of the 140 parents on history of significant nasal congestion, sneezing and/or runny nose outside periods

141 with common cold and in the relevant period of the sensitized aeroallergen.

142 Allergic sensitization was determined at age 6 years, defined as any positive skin prick test

143 (SPT) $\geq 3 \mathrm{~mm}$ (ALK-Abello, Horsholm, Denmark) or specific Immunoglobulin E (sIgE) in serum

$144 \geq 0.35 \mathrm{kUa} / \mathrm{L}$ against common inhalant and/or food allergens (ImmunoCAP; Thermo Fisher

145 Scientific, Allerod, Denmark). "Not sensitized" were both SPT and sIgE negative (Online 146 repository methods). 
148 We utilized the land cover database CORINE (https://land.copernicus.eu/) from the year 2012

149 for an unbiased definition of the living environment. Addresses at birth $(n=686)$ were

150 translated to coordinates using Google API services ${ }^{31}$. Land cover types around each

151 coordinate point were extracted from the CORINE2012 raster map (100 m resolution) with a

152 three-kilometer buffer (Table E1). The correlation matrix of proportions of five major land

153 cover types within the buffer region were analyzed with Principal Component Analysis (PCA)

15432 . The first axis explained $44 \%$ of the total variation and made clear separation between

155 artificial and natural (i.e. agricultural and forested) land cover types (Fig E1a). The first axis

156 was extracted for downstream analyses to represent a gradient of urbanization running from

157 the most rural to the most urban environments in the study region. Land cover information

158 was also dichotomized into rural and urban groups ( $\mathrm{n}_{\text {rural }}=314, \mathrm{n}_{\text {urban }}=372$; Fig E1b) with

159 Partitioning Around Medoids (PAM) clustering on Euclidean distances ${ }^{33}$. Most children

$160(n=577)$ did not move during their first year of life or moved later than 50 weeks after birth

161 ( $n=5)$. From the 109 children who did move, 77\% did not change between rural and urban

162 groups (Online repository methods).

\section{Covariates}

164 Differences between rural and urban living environments were tested for common disease-

165 associated factors including pet ownership, daycare attendance during the first year of life,

166 length of breastfeeding period, passive smoking exposure, income of family, parental

167 education, number of older siblings, home type, mode of delivery, parental diagnosis of asthma,

168 eczema and rhinitis, and use of antibiotics during the first year of life (Fig E2). 
170 Airway microbiota samples were collected at one week $(n=549)$, one $(n=647)$ and three

171 months $(n=657)$ of age ${ }^{34}$, gut microbiota samples were collected at one week $(n=544)$, one

172 month $(n=615)$ and one year $(n=625)$ of age 22 (Online repository methods).

173 DNA was extracted from airway and gut samples using the PowerMag® Soil DNA Isolation Kit

174 optimized for epMotion® (MO-BIO Laboratories, Inc., Carlsberg, CA, USA) using the

175 epMotion ${ }^{\circledR}$ robotic platform model 5075 (Eppendorf, Hamburg, Germany). The

176 manufacturer's protocol was mildly modified (described earlier ${ }^{34}$ ). Extracted DNA was stored

177 at $-20^{\circ} \mathrm{C}$ degrees prior to amplification of the $16 \mathrm{~S}$ rRNA gene variable region 4 (V4) and

178 sequencing with the Illumina MiSeq System (Illumina Inc., CA, USA) as previously described ${ }^{34}$.

179 The bioinformatics analysis pipeline is detailed in the Online repository methods.

\section{Immune mediators}

181 Airway immune mediator samples (upper airway mucosal lining fluid) were collected from one

182 month old infants $(n=620)$ with a synthetic absorptive matrix placed in both nostrils for 2

183 minutes ${ }^{35}$. Matrixes were stored immediately at $-80^{\circ} \mathrm{C}$ degrees. Blood for systemic immune

184 mediator analysis was drawn in an EDTA tube from a cubital vein at the age of 6 months

$185(\mathrm{n}=568)$, centrifuged to separate plasma and cells, and plasma was immediately stored at

$186-80^{\circ} \mathrm{C}$ until analysis ${ }^{36}$.

187 The levels of the a priori selected cyto- and chemokines ${ }^{37,38}$ were determined by using high-

188 sensitivity immunoassays based on electrochemiluminescence in a multiplex setting. Samples

189 were read in duplicates by using the Sector Imager 6000 (Meso Scale Discovery, Gaithersburg, 190 MD). 
192 Odds ratios for atopic traits in response to urban and rural (baseline) classes as well as

193 urbanization gradient were calculated with logistic regression models adjusted for lifestyle

194 variables. Adjustment included other covariates associated with urbanization (Fig E2), while

195 house type was excluded due to collinearity with the explanatory variable of interest

196 (urban/rural groups).

197 The R-package phyloseq ${ }^{39}$ was used for handling the microbiota data. Observed richness and

198 Shannon diversity were used as the alpha diversity metrics. The community compositions of

199 microbiotas (beta diversity) were visualized with Principal Coordinates Analysis (PCoA) for

200 Bray-Curtis ${ }^{40}$, Weighted UniFrac and Unweighted UniFrac ${ }^{41}$ distances and tested with

201 Permutational Multivariate Analysis of variance (PERMANOVA) ${ }^{32}$ with 1000 permutations. The

202 dissimilarities within rural and urban individuals were defined with the distance of each

203 sample from group mean ${ }^{42}$.

204 Immune mediators were log transformed and centered log ratio scaled in order to remove

205 biological variation due to differing amount of protein per volume of fluid from the dataset as

206 well as to increase the comparability between immune mediators following methodology

207 developed previously ${ }^{38}$. The normalized concentrations were tested between rural and urban

208 groups in adjusted linear models.

209 Sparse Partial Least Squares (sPLS) models with relative abundances of taxa agglomerated to

210 genus level, log-transformed, and cleaned to include those present at least in 5\% of samples

211 were used to predict the urbanization gradient 38,43 . The best model was selected based on the

212 Root Mean Squared Error (RMSE) statistics, from repeated 10-fold cross-validation, in order to

213 avoid overfitting. The predicted values from each model were extracted to represent a

214 bacterial score for the urbanization gradient. All analyses were conducted in R version 3.5.244. 


\section{Ethics statement}

216 This study was approved by the local Ethics Committee (H-B-2008-093), and the Danish Data

217 Protection Agency (2015-41-3696). Both parents gave verbal and written informed consent

218 before enrolment.

219 


\section{RESULTS}

\section{Asthma and atopic traits in rural and urban infants}

222 All subjects spent their first year of life in a westernized, densely populated, and geographically

223 concise area in Zealand (7,031 km²), Denmark (Fig 1a). Few children lived on the farms.

224 Several lifestyle variables such as pet ownership, number of older siblings, income in the family and education of the parents differed between rural and urban infants (Fig E2). Other screened variables, including mode of delivery, antibiotics during the first year of life, vitamin D or fish oil intervention groups, and atopic diseases in the parents, all previously associated with atopic

228 diseases $27,45,46$, did not differ between rural and urban infants.

230 The prevalence of asthma at six years of age or earlier was $22.3 \%(n=146)$, allergic rhinitis

$2316.8 \%(n=45)$, and eczema 31.7\% $(n=210)$. At six years of age, 31.7\% $(n=157)$ of children were 232 sensitized, of which $23.7 \%(n=117)$ had aeroallergen and $14.7 \%(n=73)$ food sensitization. The 233 prevalence of asthma, allergic rhinitis and aeroallergen sensitization at six years of age were

234 higher in children spending their first year of life in an urban compared to a rural environment

235 (Figs 1b and 1d). Allergic sensitization and eczema showed similar trends. Urban infants

236 developed more specific sensitization to peanut, house dust mite, timothy, birch, and 237 mugworth allergens (Table E2). After adjustment for lifestyle features, the odds ratios for 238 asthma (aOR 2.31, 95\% CI 1.47-3.68, P=0.0003) and aeroallergen sensitization (aOR 1.77, 95\% 239 CI 1.05-3.02, $\mathrm{P}=0.0348$ ) were increased in urban infants (Figs 1c and 1e). The adjusted, 240 predicted prevalence of asthma and aeroallergen sensitization showed a large increase along 241 the urbanization gradient while only food sensitization remained completely unrelated (Fig 242 E3). 
244 The airway microbiota at all three time points showed significant differences between rural

245 and urban infants regardless of the metric used to define the similarity of microbiota between

246 subjects (Fig E4, Table E3). These differences remained significant after adjustment for each

247 lifestyle variable as well as in a fully adjusted model (PERMANOVA, Table E4). A part of the

248 observed rural-urban differences was explained by the larger family size and more common

249 pet ownership in rural environments. Shannon diversity and richness in the airway microbiota

250 were higher in urban infants at one month of age (ANOVA, $\mathrm{P}=0.004$ and 0.005 respectively).

251 Remarkably, urban infants had more homogenous airway microbiota than rural infants at all

252 time points (i.e. urban children had more similar microbiota to each other than rural children;

253 Fig E5). Among the fifteen most abundant genera in the airways, several showed dissimilar

254 relative abundances between rural and urban infants (Fig E6). Veillonella showed a consistent

255 association with an urban living environment through all time points. Haemophilus and Rothia

256 associated with urban environment while Dolosigranulum and Moraxella associated with rural

257 environment in more than one time point (Fig. E6).

258 The composition of the gut microbiota associated with the living environment only at one year 259 of age regardless of distance metric (Fig E4, Table E3). Nevertheless, in fully adjusted model,

260 this association attenuated (Table E5), mainly due to the influence of older siblings. The fifteen

261 most abundant genera in the gut microbiota at different time points did not show differences

262 between rural and urban environments after adjustment for multiple testing (Fig E7).

263 However, the Firmicutes/Bacteroidetes-ratio was lower in rural infants at one year of age

264 (mean in rural: 3.4, urban: 4.1; ANOVA, $\mathrm{P}=0.0004$ ). A closer look at this ratio revealed that the 265 richness within Bacteroidetes was higher in rural than urban infants at the same time point 266 (mean in rural: 13.4, urban: 11.5; ANOVA, $\mathrm{P}=0.0003$ ). 
267 Relative concentrations of both airway (1 month) and systemic (6 months) immune mediators

268 differed between urban and rural infants in adjusted analyses for both sample types (Fig 2;

269 Table E6). In airways (Fig 2a), Type 2-related cytokine and chemokine concentrations showed

270 a large disparity between urban and rural infants. For example, urban infants had higher

271 relative concentrations of CCL11, CCL13 and CCL17, while CCL22 and CCL26 were higher in

272 rural infants. Furthermore, IL-12p70 (Type 1) was found in higher relative concentrations in

273 rural infants as well as IL-10 (Regulatory), which has anti-inflammatory properties. A different

274 set of immune mediators was measured in the systemic samples (Fig 2b). CXCL8 (Type 17)

275 was measured in both airway and systemic samples and showed higher relative concentration

276 in urban infants in both sample types. However, other immune mediators measured from both

277 sample types, IL-1 $\beta$ and TNF- $\alpha$, did not show similar responses.

279 Urbanized infant microbiota

280 We defined the bacterial community profiles most indicative of urbanization gradient

281 separately for each time point and sampling site. We utilized cross-validated sPLS models to

282 find a minimal (sparse) set of jointly contributing taxa that discriminated between urban and

283 rural samples. The models predicted better during later time points in both airway and gut

284 samples, indicating an accumulated influence of living environment with age (Fig 3).

285 Higher relative abundances of the genera Veillonella, Rothia, Gemella, Bergyella and

286 Streptococcus in airway microbial profiles were indicative for urban living environments, while 287 Moraxella, Paracoccus and Dolosigranulum were characteristic of a rural environment (Fig 3a) 288 at all time points corresponding to univariate analyses (Figs E6). Some airway bacteria such as 289 Bacillus and Listeria associated with a rural environment at the first week of life but the 290 direction shifted later to association with urban environments. 
291 Moraxella was also indicative for rural environment and Veillonella for urban environment in

292 the gut microbial profiles (Fig 3b), but only at a single time point each. Bifidobacterium in gut

293 was indicative for rural environment, already in the first week of life. In the gut profiles, only

294 Bacteroides switched direction from urban to rural environment at the last time point. Overall,

295 living environment-related members of gut communities did not match much between time

296 points primarily due to the low predictability at one week and one month as well as the strong

297 shifts in community composition during the first year of life (as described previously ${ }^{22}$ ).

\section{Urbanized microbial profiles, risk of disease and concentrations of immune mediators}

300 A bacterial score was extracted for each sample (how much did the composition of the sample

301 resemble the sPLS trained bacterial signature), with higher values indicating more urbanized

302 bacterial profiles in infants.

303 Having an urbanized bacterial profile in the samples was associated with higher risk of asthma

304 for all but one week gut and three months airway bacterial scores (Airway 1 week: OR 1.25,

305 95\% CI 1.01-1.55, P=0.0473; Airway 1 month: OR 1.22, 95\% CI 1.00-1.48, P=0.0498; Gut 1

306 month: OR 1.29, 95\% CI 1.05-1.59, P=0.0175; Gut 1 year: OR 1.24, 95\% CI 1.02-1.53, P=0.0368;

307 Fig 4). The risk of eczema increased only in response to an urbanized gut bacterial profile at 308 one week of age (OR 1.24, 95\% CI 1.04-1.48, P=0.0161). Similarly, the risk of sensitization was

309 restricted to one time point and compartment. An urbanized bacterial profile in gut at one year 310 of age was associated with the risk of any sensitization (OR 1.28, 95\% CI 1.03-1.59, P=0.0281)

311 and aeroallergen sensitization (OR 1.24, 95\% CI 0.98-1.57, P=0.0812) though borderline

312 significant (Fig 4).

The airway bacterial score at one month of age was correlated with immune mediator

316 concentrations at the same time point (Fig 5; Table E6) and the direction of these associations 
were similar to our comparison between urban and rural groups (Fig 2), but with important

318 distinctions. The systemic CXCL8 concentration was higher with an urbanized bacterial profile

319 (Fig 5) corresponding to results for living environment (Fig 2), but these associations were

320 borderline after correction for multiple testing. In contrast to the living environment

321 associations, airway IL-2 and IL-13 showed lower concentrations in infants with urbanized

322 bacterial profile. Bacterial scores for the gut microbiota did not significantly associate with

323 immune mediator profiles (Fig E8; Table E6).

\section{DISCUSSION}

\section{Primary Findings}

The higher risk of asthma and atopic traits in urban than in rural children is a well-established

330 phenomenon ${ }^{13}$. Our prospective, observational cohort study of 700 children supports the

331 hypothesis that the early development of the human microbiota, and its influential crosstalk

332 with the immune system, shapes the predisposition to these diseases in childhood. We found

333 that an urban living environment in infancy was associated with a higher risk of asthma and

334 aeroallergen sensitization in childhood. Urbanized microbiota both in the airways and the gut

335 in infancy was positively associated with the risk of having asthma. The urbanized gut

336 microbiota profile at one week of age also related with the risk of eczema and at one year of

337 age with allergic sensitization. Furthermore, several immune markers showed significant

338 associations with living environment related airway bacteria suggesting an influence of these

339 bacteria in immune development.

\section{Strengths and Limitations}

A major strength of the study was the extensive and prospective clinical assessment of

343 outcomes and environmental exposures. All children were uniformly diagnosed and repeatedly

344 monitored for development of symptoms of asthma and atopic traits at the COPSAC clinic, in 
345 which also microbial and immunological samples utilized in the study were collected. Our

346 definition of the living environment was based on land cover data providing unbiased

347 characterization of rural and urban individuals. However, our observational study is unable to

348 confirm causal relationships and depends on future studies with interventional or

349 experimental approaches to validate the mechanisms behind our findings. Further,

350 methodology we used for microbiota analysis can hide some details such as importance of

351 bacterial strains.

352 Even though our findings support the role of urbanized microbiota in disease development,

353 other explanatory variables can shape the risk. The examined diseases are believed to originate

354 from multiple triggers acting via a myriad of gene-environment interactions ${ }^{47}$. These can

355 include exposures other than bacteria such as indoor fungi, which has been associated with

356 childhood asthma ${ }^{48}$. Additionally, exposure to other molecules e.g. allergens may be crucial as

357 both allergens and bacterial exposure can be needed for normal immune development ${ }^{49}$.

358 Further, our analysis lacks information on (air) pollution exposure that has previously been

359 associated with the development of asthma 50 and is known to differ between rural and urban

360 Denmark ${ }^{51,52}$. Therefore, potential differences in the exposure to non-bacterial items could

361 partly explain the identified differences between living in urban or rural environment. Finally,

362 we did not have information about mothers' behavior, environment and health during

363 pregnancy, which can be important. Moreover, our cohort has limited ethnic diversity, which

364 reduces the generality of our findings.

\section{Interpretation}

Exposure to farming-associated indoor microbes, i.e. the "external" microbiota early in life is associated with asthma protection ${ }^{13-16,53}$. Here, we focused on the "internal" microbiota, i.e. the infant's own microbiota, in rural and urban children and showed corresponding findings, especially for airway microbiota. Recently, living in farm has been shown to support the 
371 development of gut microbiota in infants, which can decrease risk of asthma ${ }^{25}$. These

372 associations are also suggested by Biodiversity and Old Friends hypotheses ${ }^{54,55}$. External and

373 internal microbiotas are likely to have intimate relations. The airway microbiota is more open

374 for colonization by air-borne microbes than the gut (because inhaled microbes continuously

375 travel to the lungs) and thus reflects the external microbial exposures. Active mucosal layers in

376 the airways and lungs can respond to microbial exposures and shape the function of immune

377 system. However, as we did not sample from the gut mucosa, we cannot exclude its potential

378 importance.

379 Bacteria associated with predisposing and protective effects vary between studies ${ }^{56}$. Members

380 of urbanized bacterial communities probably act together, but Veillonella was an interesting

381 genus associated with urbanization both in the airways and the gut. Veillonella in the gut at one

382 year of age was previously associated with an increased risk of asthma in this cohort, whereas

383 another study found a protective association ${ }^{22,23}$. In contrast to our findings, airway

384 colonization with Moraxella, an opportunistic pathogen ${ }^{57}$, was previously associated with

385 increased risk of asthma ${ }^{57-59}$, also in the previous COPSAC $_{2000}$ cohort, in which culture-based

386 methodology was applied ${ }^{59}$. We suspect that the opportunistic (pathogenic) nature of some

387 urban and rural indicator bacteria, such as rural-associated Moraxella, Acinetobacter60,61 and

388 Mycobacterium ${ }^{62}$, may explain their potential importance in atopic diseases as well as their

389 cohort specific roles in diseases.

390 The hypothesized window of susceptibility, i.e. the period when extrinsic microbial stimuli can

391 permanently influence immune responsiveness, is suggested to be during the first 100 days

392 after birth ${ }^{23}$ or during the entire infancy including the prenatal period ${ }^{18}$. In this study, the

393 window associated with asthma development was the first year of life while much narrower

394 for eczema and allergic sensitization. Our study was not designed for defining such a window

395 of susceptibility, however. Previously, the window associated with asthma development has 
been restricted to shorter periods after birth (less than 100 days and less than 12 months) 23,24

397 and longer period for eczema (until 12 month of age) ${ }^{21}$, leaving it unclear when the exposure is

398 most important.

399 We found large disparities in the immune mediator concentrations between urban and rural 400 children as well as between urbanized and rural bacterial profiles. Therefore, we conclude that

401 the living environment as well as associated bacteria may influence immune function during

402 infancy. Further, our findings showed interesting similarities to our previous study discovering 403 that asthma-associated bacteria at one-month of age were positively associated with CCL2 and 404 CCL17 while negatively associated to TNF- $\alpha$ and IL-1 $\beta^{38}$. These same associations were found

405 in response to urbanized airway bacteria at one-month of age. However, in vivo cyto- and 406 chemokine concentrations do not reflect easily delimited individual immune pathways. For 407 example, both Type-2 and Type-17 related cytokines differed between rural and urban infants 408 in a non-orchestrated manner. Some individual mediators showed expected patterns such as

409 CXCL8, a neutrophil chemotactic Type-17 mediator that is enriched in moderate to severe 410 asthma ${ }^{63}$, which was increased in urban children as well as in response to urbanized airway

411 microbiota. Deficiency in regulatory responses is suspected to be important for the trajectory

412 towards hyperreactivity against allergens and development of manifest clinical allergy ${ }^{64}$.

413 Accordingly, urban infants had lower concentrations of the anti-inflammatory, regulatory type

414 mediator IL-10. Having an urbanized airway microbiota associated with decreased IL-2 in the

415 airways, which is interesting as suppressed IL-2 expression in infants has been associated with 416 food allergy 65.

417 There are several potential explanations for some immune mediator concentrations differing

418 from the expected. First, the influence of an individual mediator depends on other mediators.

419 For example, a higher concentration of IL-13 (Type-2) in response to rural airway bacteria can

420 indicate that when combined with IL-12p70, TNF- $\alpha$, IL-1 $\beta$, IL-10 and IL-2, it does not provide 
421 increased susceptibility to Type-2-based symptoms. Second, pro-inflammatory immune

422 mediators can be beneficial during certain developmental stages such as higher IL-4, IL-5 and

423 IL-13 in one-month old rural infants. Our results underscore that the current understanding

424 about an adequately stimulated immune system during different developmental stages is not

425 complete.

\section{Conclusions}

427 We found that an urbanized living environment, an urbanized microbiota in infants, in vivo

428 immune mediators and the risk of childhood asthma and atopic traits were associated, in a 429 geographically concise cohort of 700 unselected children. Our findings support an important 430 role of the infant microbiota in the association between urbanization and disease, probably via 431 crosstalk with the developing immune system.

\section{ACKNOWLEDGEMENTS}

434 We express our deepest gratitude to the children and families of the COPSAC 2010 cohort study

435 for all their support and commitment. We acknowledge and appreciate the unique efforts of 436 the COPSAC research team.

438 Authors Contributions: The guarantor of the study is HB, from conception and design, to 439 conduction of the study and acquisition of data, data analysis, and interpretation of data. JL has 440 written the first draft of the manuscript. All co-authors have provided important intellectual 441 input and contributed considerably to the analyses and interpretation of the data. All authors 442 guarantee that the accuracy and integrity of any part of the work have been appropriately 443 investigated and resolved and all have approved the final version of the manuscript. The 444 corresponding author had full access to the data and had final responsibility for the decision to 
445 submit for publication. No honorarium, grant, or other form of payment was given to any of the 446 authors to produce this manuscript.

447 Governance: We are aware of and comply with recognized codes of good research practice, 448 including the Danish Code of Conduct for Research Integrity. We comply with national and 449 international rules on the safety and rights of patients and healthy subjects, including Good 450 Clinical Practice (GCP) as defined in the EU's Directive on Good Clinical Practice, the 451 International Conference on Harmonisation's (ICH) good clinical practice guidelines and the 452 Helsinki Declaration. Privacy is important to us which is why we follow national and 453 international legislation on General Data Protection Regulation (GDPR), the Danish Act on 454 Processing of Personal Data and the practice of the Danish Data Inspectorate. 
1. Kozyrskyj AL, Becker AB. Rural-urban differences in asthma prevalence: Possible explanations. Journal of Allergy and Clinical Immunology. 2004;113:S306.

2. Rodriguez A, Vaca M, Oviedo G, Erazo S, Chico ME, Teles C, et al. Urbanisation is associated with prevalence of childhood asthma in diverse, small rural communities in Ecuador. Thorax. 2011;66:1043-50.

3. Ruokolainen L, Hertzen L von, Fyhrquist N, Laatikainen T, Lehtomäki J, Auvinen P, et al. Green areas around homes reduce atopic sensitization in children. Allergy. 2015;70:195202.

4. Christensen SH, Timm S, Janson C, Benediktsdóttir B, Forsberg B, Holm M, et al. A clear urban-rural gradient of allergic rhinitis in a population-based study in Northern Europe. Eur Clin Respir J [Internet]. 2016 [cited 2019 Jun 7];3. Available from: https://www.ncbi.nlm.nih.gov/pmc/articles/PMC5124633/

5. Hajar T, Simpson EL. The Rise in Atopic Dermatitis in Young Children: What Is the

6. von Mutius E, Smits HH. Primary prevention of asthma: from risk and protective factors to targeted strategies for prevention. The Lancet [Internet]. 2020 [cited 2020 Sep 16]; Available from: http://www.sciencedirect.com/science/article/pii/S0140673620318614

7. Strachan DP, Aït-Khaled N, Foliaki S, Mallol J, Odhiambo J, Pearce N, et al. Siblings, asthma, rhinoconjunctivitis and eczema: a worldwide perspective from the International Study of Asthma and Allergies in Childhood. Clin Exp Allergy. 2015;45:126-36.

8. Ball TM, Castro-Rodriguez JA, Griffith KA, Holberg CJ, Martinez FD, Wright AL. Siblings, Day-Care Attendance, and the Risk of Asthma and Wheezing during Childhood. New England Journal of Medicine. 2000;343:538-43.

9. Barberán A, Ladau J, Leff JW, Pollard KS, Menninger HL, Dunn RR, et al. Continental-scale distributions of dust-associated bacteria and fungi. PNAS. 2015;112:5756-61.

10. Gupta S, Hjelmsø MH, Lehtimäki J, Li X, Mortensen MS, Russel J, et al. Environmental shaping of the bacterial and fungal community in infant bed dust and correlations with the airway microbiota. Microbiome. 2020;8:115.

11. Lehtimäki J, Karkman A, Laatikainen T, Paalanen L, von Hertzen L, Haahtela T, et al. Patterns in the skin microbiota differ in children and teenagers between rural and urban environments. Scientific Reports. 2017;7:45651.

12. Ruokolainen L, Paalanen L, Karkman A, Laatikainen T, von Hertzen L, Vlasoff T, et al. Significant disparities in allergy prevalence and microbiota between the young people in Finnish and Russian Karelia. Clin Exp Allergy. 2017;47:665-74.

13. Ege MJ, Mayer M, Normand A-C, Genuneit J, Cookson WOCM, Braun-Fahrländer C, et al. Exposure to Environmental Microorganisms and Childhood Asthma. New England Journal of Medicine. 2011;364:701-9. 
14. Stein MM, Hrusch CL, Gozdz J, Igartua C, Pivniouk V, Murray SE, et al. Innate Immunity and Asthma Risk in Amish and Hutterite Farm Children. New England Journal of Medicine. 2016;375:411-21.

15. Kirjavainen PV, Karvonen AM, Adams RI, Täubel M, Roponen M, Tuoresmäki P, et al. Farmlike indoor microbiota in non-farm homes protects children from asthma development. Nature Medicine. 2019;1.

16. Schuijs MJ, Willart MA, Vergote K, Gras D, Deswarte K, Ege MJ, et al. Farm dust and endotoxin protect against allergy through A20 induction in lung epithelial cells. Science. 2015;349:1106-10.

17. Ottman N, Ruokolainen L, Suomalainen A, Sinkko H, Karisola P, Lehtimäki J, et al. Soil exposure modifies the gut microbiota and supports immune tolerance in a mouse model. Journal of Allergy and Clinical Immunology. 2019;143:1198-1206.e12.

18. Renz H, Adkins BD, Bartfeld S, Blumberg RS, Farber DL, Garssen J, et al. The neonatal window of opportunity-early priming for life. Journal of Allergy and Clinical Immunology. 2018;141:1212-4.

19. Belkaid $Y$, Hand T. Role of the Microbiota in Immunity and inflammation. Cell. 2014;157:121-41.

20. Bisgaard H, Li N, Bonnelykke K, Chawes BLK, Skov T, Paludan-Müller G, et al. Reduced diversity of the intestinal microbiota during infancy is associated with increased risk of allergic disease at school age. Journal of Allergy and Clinical Immunology. 2011;128:646652.e5.

21. Abrahamsson TR, Jakobsson HE, Andersson AF, Björkstén B, Engstrand L, Jenmalm MC. Low diversity of the gut microbiota in infants with atopic eczema. J Allergy Clin Immunol. 2012;129:434-40, 440.e1-2.

22. Stokholm J, Blaser MJ, Thorsen J, Rasmussen MA, Waage J, Vinding RK, et al. Maturation of the gut microbiome and risk of asthma in childhood. Nat Commun. 2018;9:141.

23. Arrieta M-C, Stiemsma LT, Dimitriu PA, Thorson L, Russell S, Yurist-Doutsch S, et al. Early infancy microbial and metabolic alterations affect risk of childhood asthma. Science Translational Medicine. 2015;7:307ra152-307ra152.

24. Abrahamsson TR, Jakobsson HE, Andersson AF, Björkstén B, Engstrand L, Jenmalm MC. Low gut microbiota diversity in early infancy precedes asthma at school age. Clinical \& Experimental Allergy. 2014;44:842-50.

25. Depner M, Taft DH, Kirjavainen PV, Kalanetra KM, Karvonen AM, Peschel S, et al. Maturation of the gut microbiome during the first year of life contributes to the protective farm effect on childhood asthma. Nature Medicine. 2020;1-10.

26. Bisgaard H, Vissing NH, Carson CG, Bischoff AL, Følsgaard NV, Kreiner-Møller E, et al. Deep phenotyping of the unselected COPSAC2010 birth cohort study. Clin Exp Allergy. 2013;43:1384-94. 
531

532

533

534

535

536

537

538

539

540

541

542

543

544

545

546

547

548

549

550

551

552

553

554

555

556

557

558

559

560

561

562

563

564

565

566

27. Bisgaard H, Stokholm J, Chawes BL, Vissing NH, Bjarnadóttir E, Schoos A-MM, et al. Fish Oil-Derived Fatty Acids in Pregnancy and Wheeze and Asthma in Offspring. N Engl J Med. 2016;375:2530-9.

28. Chawes BL, Bønnelykke K, Stokholm J, Vissing NH, Bjarnadóttir E, Schoos A-MM, et al. Effect of Vitamin D3 Supplementation During Pregnancy on Risk of Persistent Wheeze in the Offspring: A Randomized Clinical Trial. JAMA. 2016;315:353-61.

29. Bisgaard H, Pipper CB, Bønnelykke K. Endotyping early childhood asthma by quantitative symptom assessment. J Allergy Clin Immunol. 2011;127:1155-1164.e2.

30. Hanifin J, Rajka G. Diagnostic features of atopic dermatitis. Acta Derm Venereol. 1980;92:44-7.

31. Cooley D. googleway: Accesses Google Maps APIs to Retrieve Data and Plot Maps. R package version 2.7.1. 2018; Available from: https://CRAN.Rproject.org/package=googleway

32. Oksanen J, Blanchet FG, Friendly M, Kindt R, Legendre P, McGlinn D, et al. vegan: Community Ecology Package. 2019; Available from: https://CRAN.Rproject.org/package=vegan

33. Maechler M, Rousseeuw P, Struyf A, Hubert M, Hornik K. cluster: Cluster Analysis Basics and Extensions. R package version 2.0.7-1.2018;

34. Mortensen MS, Brejnrod AD, Roggenbuck M, Abu Al-Soud W, Balle C, Krogfelt KA, et al. The developing hypopharyngeal microbiota in early life. Microbiome. 2016;4:70.

35. Chawes BLK, Edwards MJ, Shamji B, Walker C, Nicholson GC, Tan AJ, et al. A novel method for assessing unchallenged levels of mediators in nasal epithelial lining fluid. J Allergy Clin Immunol. 2010;125:1387-1389.e3.

36. Chawes BL, Stokholm J, Bønnelykke K, Brix S, Bisgaard H. Neonates with reduced neonatal lung function have systemic low-grade inflammation. Journal of Allergy and Clinical Immunology. 2015;

37. Wolsk HM, Chawes BL, Thorsen J, Stokholm J, Bønnelykke K, Brix S, et al. Noninvasive Sampling of Mucosal Lining Fluid for the Quantification of In Vivo Upper Airway Immunemediator Levels. J Vis Exp. 2017;

38. Thorsen J, Rasmussen MA, Waage J, Mortensen M, Brejnrod A, Bønnelykke K, et al. Infant airway microbiota and topical immune perturbations in the origins of childhood asthma. Nature Communications. 2019;10:1-8.

39. McMurdie PJ, Holmes S. phyloseq: An R Package for Reproducible Interactive Analysis and Graphics of Microbiome Census Data. PLoS ONE. 2013;8:e61217.

40. Bray JR, Curtis JT. An Ordination of the Upland Forest Communities of Southern Wisconsin. Ecological Monographs. 1957;27:325-49. 
41. Lozupone CA, Hamady M, Kelley ST, Knight R. Quantitative and Qualitative $\beta$ Diversity Measures Lead to Different Insights into Factors That Structure Microbial Communities. Appl Environ Microbiol. 2007;73:1576-85.

42. Lahti L. microbiome R package. Available from: http://microbiome.github.io

43. Rohart F, Gautier B, Singh A, Cao K-AL. mixOmics: An R package for 'omics feature selection and multiple data integration. PLOS Computational Biology. 2017;13:e1005752.

44. R Core Team. R: A language and environment for statistical computing. R Foundation for Statistical Computing, Vienna, Austria. [Internet]. 2018. Available from: https://www.Rproject.org/.

45. van Nimwegen FA, Penders J, Stobberingh EE, Postma DS, Koppelman GH, Kerkhof M, et al. Mode and place of delivery, gastrointestinal microbiota, and their influence on asthma and atopy. J Allergy Clin Immunol. 2011;128:948-955.e1-3.

46. Russell SL, Gold MJ, Hartmann M, Willing BP, Thorson L, Wlodarska M, et al. Early life antibiotic-driven changes in microbiota enhance susceptibility to allergic asthma. EMBO Rep. 2012;13:440-7.

47. Cecchi L, D'Amato G, Annesi-Maesano I. External exposome and allergic respiratory and skin diseases. J Allergy Clin Immunol. 2018;141:846-57.

48. Sharpe RA, Bearman N, Thornton CR, Husk K, Osborne NJ. Indoor fungal diversity and asthma: A meta-analysis and systematic review of risk factors. Journal of Allergy and Clinical Immunology. 2015;135:110-22.

49. Lynch SV, Wood RA, Boushey H, Bacharier LB, Bloomberg GR, Kattan M, et al. Effects of early-life exposure to allergens and bacteria on recurrent wheeze and atopy in urban children. Journal of Allergy and Clinical Immunology. 2014;134:593-601.e12.

50. Carlsten C, Rider CF. Traffic-related air pollution and allergic disease: an update in the context of global urbanization. Curr Opin Allergy Clin Immunol. 2017;17:85-9.

51. Brønnum-Hansen H, Bender AM, Andersen ZJ, Sørensen J, Bønløkke JH, Boshuizen H, et al. Assessment of impact of traffic-related air pollution on morbidity and mortality in Copenhagen Municipality and the health gain of reduced exposure. Environment International. 2018;121:973-80.

52. Fauser P, Ketzel M, Becker T, Plejdrup MS, Brandt J, Gidhagen L, et al. Human exposure to carcinogens in ambient air in Denmark, Finland and Sweden. Atmospheric Environment. 2017;167:283-97.

53. von Mutius E, Vercelli D. Farm living: effects on childhood asthma and allergy. Nature Reviews Immunology. 2010;10:861-8.

54. von Hertzen L, Hanski I, Haahtela T. Natural immunity. Biodiversity loss and inflammatory diseases are two global megatrends that might be related. EMBO Rep. 2011;12:1089-93. 
55. Rook GA. Regulation of the immune system by biodiversity from the natural environment: An ecosystem service essential to health. PNAS. 2013;110:18360-7.

56. Karkman A, Lehtimäki J, Ruokolainen L. The ecology of human microbiota: dynamics and diversity in health and disease. Ann N Y Acad Sci. 2017;1399:78-92.

57. Larsen JM, Brix S, Thysen AH, Birch S, Rasmussen MA, Bisgaard H. Children with asthma by school age display aberrant immune responses to pathogenic airway bacteria as infants. J Allergy Clin Immunol. 2014;

58. Chung KF. Airway microbial dysbiosis in asthmatic patients: A target for prevention and treatment? Journal of Allergy and Clinical Immunology. 2017;139:1071-81.

59. Bisgaard H, Hermansen MN, Buchvald F, Loland L, Halkjaer LB, Bønnelykke K, et al. Childhood Asthma after Bacterial Colonization of the Airway in Neonates. New England Journal of Medicine. 2007;357:1487-95.

60. Hanski I, Hertzen L von, Fyhrquist N, Koskinen K, Torppa K, Laatikainen T, et al. Environmental biodiversity, human microbiota, and allergy are interrelated. PNAS. 2012;109:8334-9.

61. Debarry J, Hanuszkiewicz A, Stein K, Holst O, Heine H. The allergy-protective properties of Acinetobacter lwoffii F78 are imparted by its lipopolysaccharide. Allergy. 2010;65:690-7.

62. Hopkin JM. Atopy, asthma, and the mycobacteria. Thorax. 2000;55:443-5.

63. Gras D, Martinez-Anton A, Bourdin A, Garulli C, de Senneville L, Vachier I, et al. Human bronchial epithelium orchestrates dendritic cell activation in severe asthma. Eur Respir J. $2017 ; 49$.

64. Lambrecht BN, Hammad H. The immunology of asthma. Nature Immunology. 2015;16:4556.

65. Zhang Y, Collier F, Naselli G, Saffery R, Tang ML, Allen KJ, et al. Cord blood monocytederived inflammatory cytokines suppress IL-2 and induce nonclassic "TH2-type" immunity associated with development of food allergy. Science Translational Medicine. 2016;8:321ra8-321ra8. 
649

650

651

652

653

654

655

656

657

658

659

660

661

662

663

664

665

666

667

668

669

670

671

672

673

674

675

676

677

678

679

680

681

682

683

684

685

686

687

688

689

690

691

692

693

694

695

696

697

698

699

700

\section{Figure legends}

Figure 1. Prevalence of asthma and atopic diseases in rural and urban infants. The proportions of main land cover types in a radius of $3 \mathrm{~km}$ around the home at birth are condensed to a gradient from mostly rural to highly urbanized living environments by Principal Components Analysis (PCA). Figure a shows geographical distribution of children, colored by the urbanization gradient. Urban children are mainly clustered around the capital, Copenhagen, as expected. Coordinate information is slightly jittered on the map to preserve anonymity. Figures $\mathbf{b}$ and $\mathbf{d}$ show the crude prevalence of outcomes at six years of age in children living in urban and rural environment during infancy. Differences are tested with Fisher's exact tests. Figures $\mathbf{c}$ and $\mathbf{e}$ show the adjusted odds ratios from logistic regression models for the outcomes in urban vs. rural (baseline) living environment. Urban infants have increased risk for asthma and aeroallergen sensitization. Analyses are adjusted for socio-economics, pet ownership, older siblings, passive smoking exposure and total length of breastfeeding.

Figure 2. Relative concentration of airway and systemic immune mediators differ between urban and rural infants. The airway immune profile at one month of age $(n=586, a)$ and systemic immune profile at six months of age $(n=665, \mathbf{b})$ in response to urban and rural classes defined by linear models adjusted for living environment associated lifestyle features. Positive estimates indicate higher relative concentration in urban infants while negative estimates indicate higher relative concentration in rural infants. Error bars represent the 95\% CI. False positive rate corrected p-values are presented in Table E6.

Figure 3. The composition of living environment-related microbial profiles for each time point. sparse Partial Least Squares (sPLS) models were run for (sub-)genera present in at least 5\% of samples. Selection of the best model for each time point was done by comparing Root Mean Square Error (RMSE) values between models with differing numbers of taxa and components. Each selected model for airway (a) and gut (b) microbiota had one component. Included taxa were ordered in the heatmap by their summed loadings across all time points. Taxa with positive loadings are more common in urban (gold) living environments, while taxa with negative loadings are more common in rural (green) living environments. Taxa colored white are not included in the present model.

Figure 4. Airway and gut bacterial scores indicative of living environment and the risk of asthma and atopic traits at 6 years of age. Bacterial scores were scaled to a standard deviation of one in order to ease interpretation. For airways (a-c), the risk of developing asthma increases with higher values of bacterial score, i.e. urban-like bacterial profiles at one week and one month of age. For gut (df), eczema associates with the bacterial score from one week (d), while the one-month and one-year time points are important for asthma development (e). The risk of sensitization increases with higher values of the gut bacterial score at one year of age (f). Error bars represent the $95 \% \mathrm{CI}$.

Figure 5. Airway bacterial score versus the relative concentration of airway and systemic immune mediators. The figure shows normalized and scaled relative concentrations of immune mediators in relation to airway bacterial score per standard deviation. Higher values indicate association with an urban-like bacterial community composition. Panel A shows the topical immune mediators at one month of age, and panel B the systemic immune mediators at six months of age in response to bacterial scores. Linear models were adjusted for living environment associated lifestyle features. Error bars represent 95\% CI. False positive rate corrected p-values are presented in Table E6. 


\begin{tabular}{cccccc}
\multirow{2}{*}{ Buffer } & \multicolumn{2}{c}{ Rural } & \multicolumn{2}{c}{ Urban } & Silhouette \\
& $\mathbf{n}$ & $\mathbf{\%}$ & $\mathbf{n}$ & $\mathbf{\%}$ & width \\
\hline \hline $\mathbf{3} \mathbf{~ k m}$ & 314 & 45.8 & 372 & 54.2 & 0.61 \\
$\mathbf{1 ~} \mathbf{~ k m}$ & 204 & 29.7 & 482 & 70.3 & 0.70 \\
$\mathbf{5 0 0 ~} \mathbf{~ m}$ & 134 & 19.5 & 552 & 80.5 & 0.78
\end{tabular}




\begin{tabular}{|c|c|c|c|c|c|c|c|c|c|c|c|c|}
\hline & & & Rur & $\mathrm{al}(\mathrm{n}=23$ & & & & Urb & an $(n=2 \varepsilon$ & & & $p$-value \\
\hline & specific IgE & $\%>0.35$ & $\mathrm{n}>0.35$ & median & mean & range & $\%>0.35$ & $\mathrm{n}>0.35$ & median & mean & range & $(>0.35)$ \\
\hline & Egg & 6.7 & 16 & 0 & 0.06 & $0 ; 2.01$ & 5.9 & 17 & 0 & 0.11 & $0 ; 16.96$ & 0.72 \\
\hline & Milk & 9.7 & 23 & 0 & 0.09 & $0 ; 2.56$ & 7.6 & 22 & 0 & 0.09 & $0 ; 3.46$ & 0.53 \\
\hline ㅇำ & Wheat & 5.0 & 12 & 0 & 0.05 & $0 ; 1.70$ & 5.5 & 16 & 0 & 0.12 & $0 ; 4.85$ & 1 \\
\hline & Peanut & 0.8 & 2 & 0 & 0.01 & $0 ; 0.54$ & 3.8 & 11 & 0 & 0.13 & $0 ; 15.54$ & 0.045 \\
\hline & Seafood & 0.8 & 2 & 0 & 0.04 & $0 ; 7.49$ & 2.4 & 7 & 0 & 0.19 & $0 ; 37.45$ & 0.19 \\
\hline & House dust mite & 6.7 & 16 & 0 & 3.07 & $0 ; 100$ & 12.1 & 35 & 0 & 2.50 & $0 ; 100$ & 0.039 \\
\hline & Cat & 2.9 & 7 & 0 & 0.51 & $0 ; 100$ & 3.5 & 10 & 0 & 1.47 & $0 ; 100$ & 0.81 \\
\hline 苾 & Dog & 2.1 & 5 & 0 & 0.17 & $0 ; 36.08$ & 3.5 & 10 & 0 & 0.28 & $0 ; 49.91$ & 0.44 \\
\hline$\frac{\mathscr{J}}{\bar{\pi}}$ & Horse & 0.4 & 1 & 0 & 0.08 & $0 ; 18.10$ & 0.7 & 2 & 0 & 0.02 & $0 ; 2.58$ & 1 \\
\hline$\frac{O}{Q}$ & Timothy & 6.7 & 16 & 0 & 0.12 & $0 ; 6.08$ & 14.2 & 41 & 0 & 3.2 & $0 ; 100$ & 0.007 \\
\hline & Birch & 3.8 & 9 & 0 & 0.9 & $0 ; 100$ & 9.7 & 28 & 0 & 2.29 & $0 ; 100$ & 0.006 \\
\hline & Mugworth & 1.7 & 4 & 0 & 0.02 & $0 ; 0.81$ & 6.6 & 19 & 0 & 0.19 & $0 ; 18.94$ & 0.005 \\
\hline & C. Herbarum & 0.4 & 1 & 0 & 0.02 & $0 ; 5.28$ & 1.0 & 3 & 0 & 0.02 & $0 ; 1.57$ & 0.63 \\
\hline$\frac{0}{2}$ & A. Fumigatus & 0.4 & 1 & 0 & 0 & $0 ; 0.98$ & 0 & 0 & 0 & 0 & $0 ; 0.2$ & 0.45 \\
\hline & A. Tenuis & 0.4 & 1 & 0 & 0.14 & $0 ; 33.96$ & 1.4 & 4 & 0 & 0.03 & $0 ; 4.65$ & 0.38 \\
\hline
\end{tabular}




\begin{tabular}{|c|c|c|c|c|c|c|c|c|}
\hline \multirow[t]{2}{*}{ Body site } & \multirow[t]{2}{*}{ Age } & \multirow[t]{2}{*}{$\mathbf{n}$} & \multicolumn{2}{|c|}{ Bray-Curtis } & \multicolumn{2}{|c|}{ Weighted UniFrac } & \multicolumn{2}{|c|}{ Unweighted Unifrac } \\
\hline & & & $\mathrm{R} 2$ & $p$ & $\mathrm{R} 2$ & $p$ & $\mathrm{R} 2$ & $\mathrm{p}$ \\
\hline \multirow{3}{*}{ Gut } & 1 week & 547 & 0.002 & 0.3 & 0.003 & 0.2 & 0.001 & 0.8 \\
\hline & 1 month & 600 & 0.001 & 0.9 & 0.001 & 0.5 & 0.002 & 0.2 \\
\hline & 1 year & 612 & 0.003 & 0.005 & 0.004 & 0.02 & 0.003 & 0.005 \\
\hline \multirow{3}{*}{ Airways } & 1 week & 538 & 0.006 & 0.001 & 0.008 & 0.001 & 0.003 & 0.038 \\
\hline & 1 month & 629 & 0.006 & 0.001 & 0.007 & 0.001 & 0.004 & 0.002 \\
\hline & 3 months & 633 & 0.006 & 0.001 & 0.007 & 0.001 & 0.004 & 0.002 \\
\hline
\end{tabular}


Airway microbiota

\begin{tabular}{ccccccccccc} 
& \multicolumn{3}{c}{1 week } & \multicolumn{3}{c}{1 month } & \multicolumn{3}{c}{3 months } \\
Living environment gradient + & $n$ & $R 2$ & $p$ & $n$ & $R 2$ & $p$ & $n$ & $R 2$ & $p$ \\
\hline \hline Unadjusted model & 538 & 0.005 & 0.001 & $\mathbf{6 2 9}$ & $\mathbf{0 . 0 0 6}$ & $\mathbf{0 . 0 0 1}$ & $\mathbf{6 3 3}$ & $\mathbf{0 . 0 0 6}$ & $\mathbf{0 . 0 0 1}$ \\
Furry pet at home & $\mathbf{5 3 0}$ & $\mathbf{0 . 0 0 4}$ & $\mathbf{0 . 0 0 1}$ & $\mathbf{6 2 2}$ & $\mathbf{0 . 0 0 3}$ & $\mathbf{0 . 0 0 2}$ & $\mathbf{6 2 4}$ & $\mathbf{0 . 0 0 5}$ & $\mathbf{0 . 0 0 1}$ \\
Daycare attendance before age 1 & $\mathbf{5 3 8}$ & $\mathbf{0 . 0 0 6}$ & $\mathbf{0 . 0 0 1}$ & $\mathbf{6 2 9}$ & $\mathbf{0 . 0 0 6}$ & $\mathbf{0 . 0 0 1}$ & $\mathbf{6 3 3}$ & $\mathbf{0 . 0 0 6}$ & $\mathbf{0 . 0 0 1}$ \\
Total breastfeeding duration & $\mathbf{5 3 3}$ & $\mathbf{0 . 0 0 5}$ & $\mathbf{0 . 0 0 1}$ & $\mathbf{6 2 6}$ & $\mathbf{0 . 0 0 7}$ & $\mathbf{0 . 0 0 1}$ & $\mathbf{6 2 8}$ & $\mathbf{0 . 0 0 6}$ & $\mathbf{0 . 0 0 1}$ \\
Passive smoking exposure & $\mathbf{5 3 0}$ & $\mathbf{0 . 0 0 5}$ & $\mathbf{0 . 0 0 1}$ & $\mathbf{6 2 2}$ & $\mathbf{0 . 0 0 7}$ & $\mathbf{0 . 0 0 1}$ & $\mathbf{6 2 4}$ & $\mathbf{0 . 0 0 6}$ & $\mathbf{0 . 0 0 1}$ \\
Socio-economics & $\mathbf{5 1 6}$ & $\mathbf{0 . 0 0 5}$ & $\mathbf{0 . 0 0 1}$ & $\mathbf{6 0 4}$ & $\mathbf{0 . 0 0 7}$ & $\mathbf{0 . 0 0 1}$ & $\mathbf{6 0 9}$ & $\mathbf{0 . 0 0 6}$ & $\mathbf{0 . 0 0 1}$ \\
Older siblings & $\mathbf{5 3 1}$ & $\mathbf{0 . 0 0 5}$ & $\mathbf{0 . 0 0 1}$ & $\mathbf{6 2 2}$ & $\mathbf{0 . 0 0 5}$ & $\mathbf{0 . 0 0 1}$ & $\mathbf{6 2 6}$ & $\mathbf{0 . 0 0 4}$ & $\mathbf{0 . 0 0 1}$ \\
Adjusted for all & $\mathbf{5 1 4}$ & $\mathbf{0 . 0 0 4}$ & $\mathbf{0 . 0 0 2}$ & $\mathbf{6 0 2}$ & $\mathbf{0 . 0 0 5}$ & $\mathbf{0 . 0 0 1}$ & $\mathbf{6 0 5}$ & $\mathbf{0 . 0 0 4}$ & $\mathbf{0 . 0 0 2}$
\end{tabular}




\section{Gut microbiota}

\begin{tabular}{cccccccccc} 
Living environment gradient + & \multicolumn{3}{c}{1 week } & \multicolumn{3}{c}{1 month } & \multicolumn{3}{c}{ 1year } \\
& $\mathbf{n}$ & $\mathbf{R} \mathbf{2}$ & $\boldsymbol{p}$ & $\boldsymbol{n}$ & $\boldsymbol{R 2}$ & $\boldsymbol{p}$ & $\boldsymbol{n}$ & $\boldsymbol{R 2}$ & $\boldsymbol{p}$ \\
\hline \hline Unadjusted model & 547 & 0.002 & 0.3 & 600 & 0.002 & 0.6 & $\mathbf{6 1 2}$ & $\mathbf{0 . 0 0 4}$ & $\mathbf{0 . 0 0 2}$ \\
Furry pet at home & 540 & 0.002 & 0.2 & 591 & 0.002 & 0.6 & $\mathbf{6 0 9}$ & $\mathbf{0 . 0 0 3}$ & $\mathbf{0 . 0 0 3}$ \\
Daycare attendance before age 1 & 547 & 0.002 & 0.4 & 600 & 0.001 & 0.7 & $\mathbf{6 1 2}$ & $\mathbf{0 . 0 0 4}$ & $\mathbf{0 . 0 0 2}$ \\
Total breastfeeding duration & 543 & 0.002 & 0.4 & 595 & 0.002 & 0.5 & $\mathbf{6 1 0}$ & $\mathbf{0 . 0 0 4}$ & $\mathbf{0 . 0 0 2}$ \\
Passive smoking exposure & 540 & 0.002 & 0.3 & 591 & 0.002 & 0.7 & $\mathbf{6 0 9}$ & $\mathbf{0 . 0 0 4}$ & $\mathbf{0 . 0 0 1}$ \\
Socio-economics & 527 & 0.002 & 0.3 & 574 & 0.002 & 0.5 & $\mathbf{5 9 2}$ & $\mathbf{0 . 0 0 4}$ & $\mathbf{0 . 0 0 1}$ \\
Older siblings & 541 & 0.002 & 0.3 & 592 & 0.002 & 0.6 & $\mathbf{6 1 1}$ & $\mathbf{0 . 0 0 2}$ & $\mathbf{0 . 0 4}$ \\
Adjusted for all & 525 & 0.002 & 0.2 & 572 & 0.001 & 0.8 & $\mathbf{5 8 9}$ & 0.002 & 0.2
\end{tabular}




\begin{tabular}{|c|c|c|c|c|c|c|c|c|c|}
\hline $\begin{array}{l}\text { Explana- } \\
\text { tory } \\
\text { variable }\end{array}$ & Time & $\begin{array}{l}\text { Immune } \\
\text { marker }\end{array}$ & $\begin{array}{l}\text { Immune } \\
\text { response } \\
\text { type }\end{array}$ & Estimate & Std.error & Conf.low & Conf.high & p-value & q-value \\
\hline \multirow{25}{*}{ 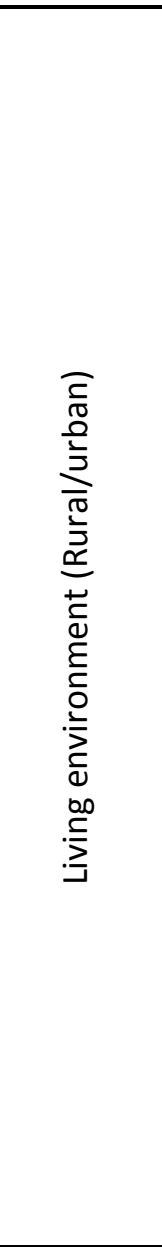 } & \multirow{20}{*}{$\begin{array}{l}\text { One } \\
\text { month }\end{array}$} & CCL2 & Type 1 & 1.346 & 0.091 & 1.125 & 1.610 & 0.001 & 0.006 \\
\hline & & CCL4 & Type 1 & 1.176 & 0.09 & 0.985 & 1.404 & 0.074 & 0.134 \\
\hline & & CXCL10 & Type 1 & 1.116 & 0.093 & 0.931 & 1.339 & 0.236 & 0.363 \\
\hline & & IFNg & Type 1 & 1.027 & 0.095 & 0.854 & 1.236 & 0.776 & 0.786 \\
\hline & & IL12p70 & Type 1 & 0.778 & 0.092 & 0.649 & 0.931 & 0.006 & 0.018 \\
\hline & & TNFa & Type 1 & 1.104 & 0.093 & 0.92 & 1.325 & 0.287 & 0.383 \\
\hline & & CCL11 & Type 2 & 1.344 & 0.091 & 1.125 & 1.607 & 0.001 & 0.006 \\
\hline & & CCL13 & Type 2 & 1.360 & 0.09 & 1.139 & 1.624 & 0.001 & 0.006 \\
\hline & & CCL17 & Type 2 & 1.301 & 0.087 & 1.097 & 1.544 & 0.003 & 0.009 \\
\hline & & CCL22 & Type 2 & 0.724 & 0.09 & 0.607 & 0.863 & 0 & 0.006 \\
\hline & & CCL26 & Type 2 & 0.792 & 0.092 & 0.662 & 0.949 & 0.012 & 0.026 \\
\hline & & IL13 & Type 2 & 0.842 & 0.094 & 0.701 & 1.011 & 0.066 & 0.132 \\
\hline & & IL4 & Type 2 & 0.903 & 0.093 & 0.753 & 1.084 & 0.275 & 0.383 \\
\hline & & IL5 & Type 2 & 0.875 & 0.094 & 0.728 & 1.051 & 0.154 & 0.257 \\
\hline & & CXCL8 & Type 17 & 1.267 & 0.091 & 1.061 & 1.513 & 0.009 & 0.023 \\
\hline & & IL17 & Type 17 & 1.097 & 0.093 & 0.915 & 1.317 & 0.318 & 0.398 \\
\hline & & IL1b & Type 17 & 0.942 & 0.092 & 0.786 & 1.128 & 0.514 & 0.604 \\
\hline & & IL10 & Regulatory & 0.749 & 0.092 & 0.625 & 0.898 & 0.002 & 0.008 \\
\hline & & IL2 & Regulatory & 0.975 & 0.093 & 0.812 & 1.171 & 0.786 & 0.786 \\
\hline & & TGFb1 & Regulatory & 1.035 & 0.092 & 0.864 & 1.241 & 0.708 & 0.786 \\
\hline & \multirow{5}{*}{$\begin{array}{c}\text { Six } \\
\text { months }\end{array}$} & TNFa & Type 1 & 0.867 & 0.09 & 0.727 & 1.034 & 0.113 & 0.188 \\
\hline & & CXCL8 & Type 17 & 1.450 & 0.087 & 1.223 & 1.720 & 0 & 0 \\
\hline & & IL1b & Type 17 & 0.704 & 0.089 & 0.591 & 0.837 & 0 & 0 \\
\hline & & IL6 & Type 17 & 0.918 & 0.092 & 0.766 & 1.101 & 0.357 & 0.357 \\
\hline & & CRP & Generic & 1.129 & 0.09 & 0.947 & 1.345 & 0.177 & 0.221 \\
\hline \multirow{20}{*}{ 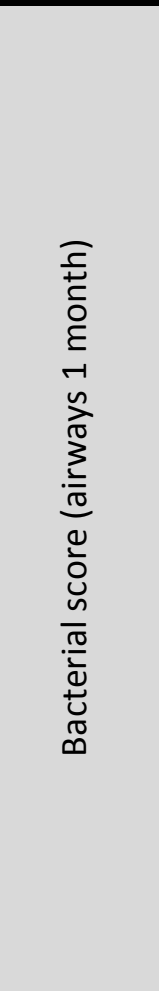 } & \multirow{20}{*}{$\begin{array}{c}\text { One } \\
\text { month }\end{array}$} & $\overline{\mathrm{CCL} 2}$ & Type 1 & 1.107 & 0.044 & 1.015 & 1.207 & 0.022 & 0.063 \\
\hline & & CCL4 & Type 1 & 0.96 & 0.043 & 0.882 & 1.044 & 0.34 & 0.433 \\
\hline & & CXCL10 & Type 1 & 1.043 & 0.045 & 0.956 & 1.138 & 0.346 & 0.433 \\
\hline & & IFNg & Type 1 & 1.043 & 0.044 & 0.958 & 1.136 & 0.334 & 0.433 \\
\hline & & IL12p70 & Type 1 & 0.909 & 0.044 & 0.833 & 0.992 & 0.033 & 0.077 \\
\hline & & TNFa & Type 1 & 0.9 & 0.043 & 0.826 & 0.98 & 0.015 & 0.056 \\
\hline & & CCL11 & Type 2 & 1.048 & 0.044 & 0.962 & 1.142 & 0.28 & 0.431 \\
\hline & & CCL13 & Type 2 & 1.086 & 0.043 & 0.998 & 1.182 & 0.056 & 0.101 \\
\hline & & CCL17 & Type 2 & 1.125 & 0.041 & 1.038 & 1.219 & 0.004 & 0.021 \\
\hline & & CCL22 & Type 2 & 1.031 & 0.043 & 0.948 & 1.121 & 0.479 & 0.563 \\
\hline & & CCL26 & Type 2 & 0.977 & 0.044 & 0.896 & 1.065 & 0.599 & 0.666 \\
\hline & & IL13 & Type 2 & 0.877 & 0.045 & 0.804 & 0.958 & 0.004 & 0.021 \\
\hline & & IL4 & Type 2 & 0.981 & 0.045 & 0.899 & 1.070 & 0.661 & 0.696 \\
\hline & & IL5 & Type 2 & 1.066 & 0.043 & 0.979 & 1.159 & 0.141 & 0.235 \\
\hline & & CXCL8 & Type 17 & 0.919 & 0.04 & 0.849 & 0.995 & 0.037 & 0.077 \\
\hline & & IL17 & Type 17 & 0.913 & 0.044 & 0.837 & 0.995 & 0.039 & 0.077 \\
\hline & & IL1b & Type 17 & 0.863 & 0.043 & 0.793 & 0.94 & 0.001 & 0.011 \\
\hline & & IL10 & Regulatory & 0.902 & 0.043 & 0.83 & 0.981 & 0.017 & 0.056 \\
\hline & & IL2 & Regulatory & 0.867 & 0.044 & 0.796 & 0.944 & 0.001 & 0.011 \\
\hline & & TGFb1 & Regulatory & 1.007 & 0.044 & 0.924 & 1.098 & 0.866 & 0.866 \\
\hline \multirow{3}{*}{ 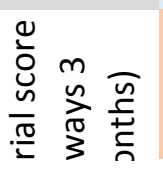 } & \multirow{3}{*}{$\underset{\substack{\text { Six } \\
n \cap n+h}}{ }$} & TNFa & Type 1 & 0.946 & 0.042 & 0.871 & 1.027 & 0.183 & 0.458 \\
\hline & & CXCL8 & Type 17 & 1.102 & 0.041 & 1.017 & 1.193 & 0.017 & 0.087 \\
\hline & & IL1b & Type 17 & 1.009 & 0.041 & 0.931 & 1.094 & 0.823 & 0.956 \\
\hline
\end{tabular}




\begin{tabular}{|c|c|c|c|c|c|c|c|c|c|}
\hline 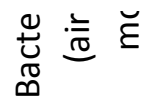 & & $\begin{array}{l}\text { IL6 } \\
\text { CRP }\end{array}$ & $\begin{array}{l}\text { Type } 17 \\
\text { Generic }\end{array}$ & $\begin{array}{l}1.002 \\
0.977\end{array}$ & $\begin{array}{l}0.043 \\
0.042\end{array}$ & $\begin{array}{c}0.922 \\
0.9\end{array}$ & $\begin{array}{l}1.089 \\
1.060\end{array}$ & $\begin{array}{l}0.956 \\
0.573\end{array}$ & $\begin{array}{l}0.956 \\
0.956\end{array}$ \\
\hline \multirow{25}{*}{ 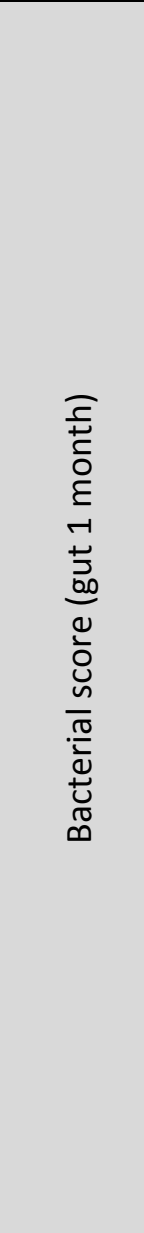 } & \multirow{20}{*}{$\begin{array}{l}\text { One } \\
\text { month }\end{array}$} & $\overline{C C L 2}$ & Type 1 & 1.038 & 0.043 & 0.954 & 1.129 & 0.391 & 0.784 \\
\hline & & CCL4 & Type 1 & 1.001 & 0.042 & 0.922 & 1.087 & 0.982 & 0.982 \\
\hline & & CXCL10 & Type 1 & 1.025 & 0.043 & 0.942 & 1.115 & 0.57 & 0.784 \\
\hline & & IFNg & Type 1 & 0.987 & 0.045 & 0.904 & 1.078 & 0.772 & 0.908 \\
\hline & & IL12p70 & Type 1 & 0.978 & 0.044 & 0.897 & 1.066 & 0.617 & 0.784 \\
\hline & & TNFa & Type 1 & 0.968 & 0.043 & 0.888 & 1.054 & 0.448 & 0.784 \\
\hline & & CCL11 & Type 2 & 1.043 & 0.043 & 0.959 & 1.134 & 0.328 & 0.784 \\
\hline & & CCL13 & Type 2 & 1.054 & 0.041 & 0.972 & 1.142 & 0.204 & 0.784 \\
\hline & & CCL17 & Type 2 & 1.034 & 0.041 & 0.953 & 1.121 & 0.419 & 0.784 \\
\hline & & CCL22 & Type 2 & 0.975 & 0.041 & 0.899 & 1.057 & 0.539 & 0.784 \\
\hline & & CCL26 & Type 2 & 1.001 & 0.043 & 0.92 & 1.089 & 0.979 & 0.982 \\
\hline & & IL13 & Type 2 & 0.913 & 0.044 & 0.837 & 0.995 & 0.04 & 0.784 \\
\hline & & IL4 & Type 2 & 0.963 & 0.044 & 0.884 & 1.049 & 0.386 & 0.784 \\
\hline & & IL5 & Type 2 & 1.024 & 0.043 & 0.942 & 1.114 & 0.579 & 0.784 \\
\hline & & CXCL8 & Type 17 & 1.023 & 0.043 & 0.941 & 1.112 & 0.589 & 0.784 \\
\hline & & IL17 & Type 17 & 1.067 & 0.043 & 0.981 & 1.162 & 0.132 & 0.784 \\
\hline & & IL1b & Type 17 & 0.992 & 0.043 & 0.912 & 1.079 & 0.85 & 0.944 \\
\hline & & IL10 & Regulatory & 1.036 & 0.044 & 0.951 & 1.128 & 0.417 & 0.784 \\
\hline & & IL2 & Regulatory & 0.974 & 0.044 & 0.894 & 1.062 & 0.553 & 0.784 \\
\hline & & TGFb1 & Regulatory & 1.021 & 0.043 & 0.938 & 1.112 & 0.627 & 0.784 \\
\hline & \multirow{5}{*}{$\begin{array}{c}\text { Six } \\
\text { months }\end{array}$} & TNFa & Type 1 & 1.002 & 0.043 & 0.922 & 1.089 & 0.969 & 0.969 \\
\hline & & CXCL8 & Type 17 & 1.046 & 0.041 & 0.966 & 1.132 & 0.272 & 0.676 \\
\hline & & IL1b & Type 17 & 0.966 & 0.041 & 0.892 & 1.047 & 0.405 & 0.676 \\
\hline & & IL6 & Type 17 & 1.010 & 0.043 & 0.928 & 1.100 & 0.812 & 0.969 \\
\hline & & CRP & Generic & 1.060 & 0.042 & 0.976 & 1.152 & 0.165 & 0.676 \\
\hline
\end{tabular}


a

Zealand, Denmark

I.

Urban

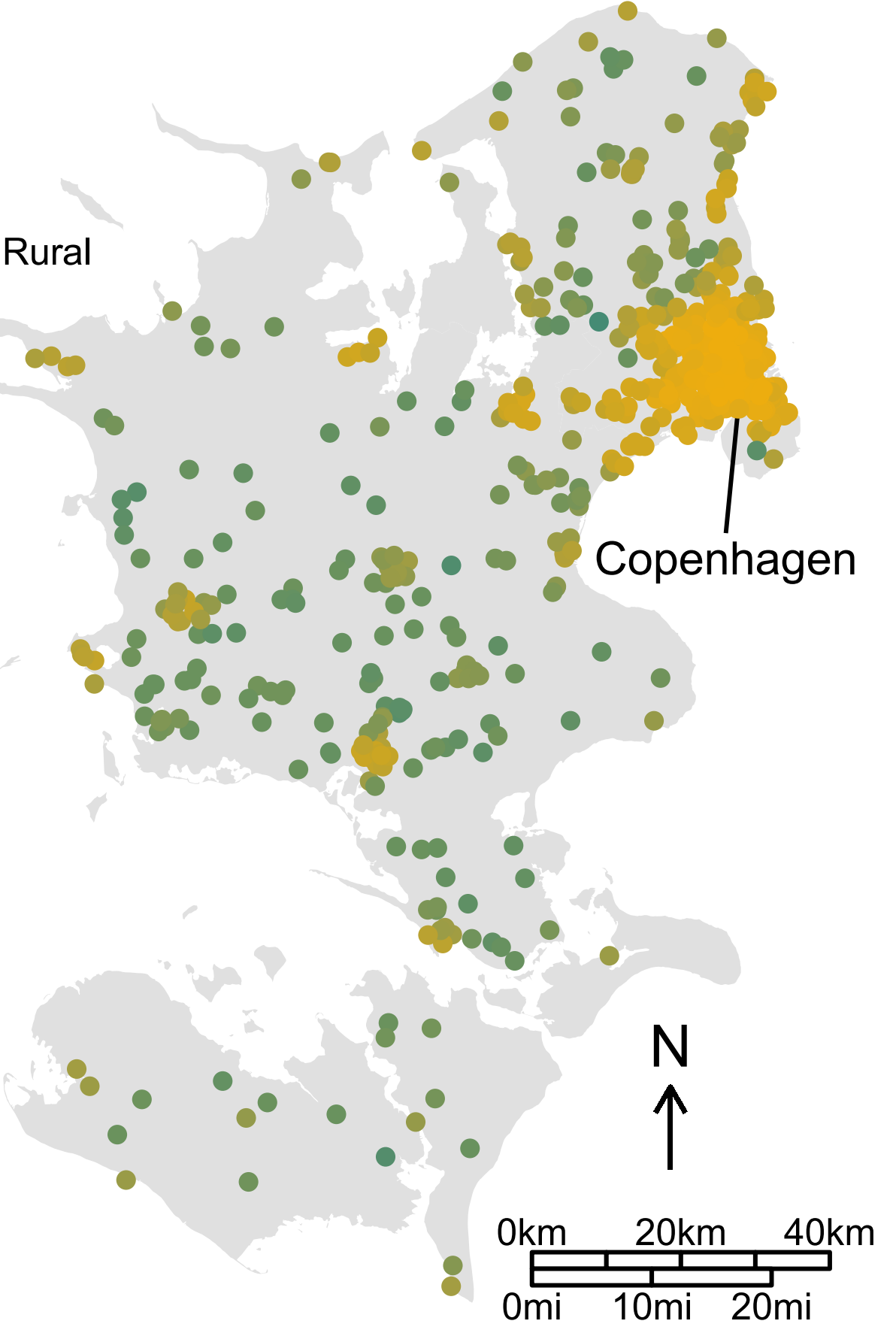

Asthma

$n=146 / 653$

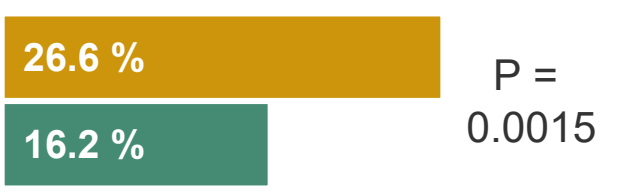

Eczema

$n=210 / 662$

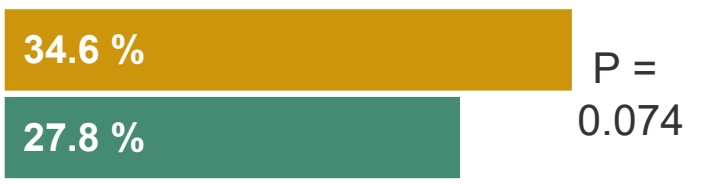

Allergic rhinitis

$n=45 / 659$

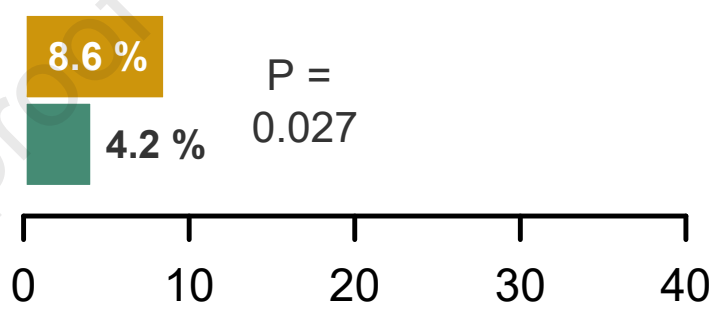

d

Any sensitization $n=157 / 495$

\section{Aeroallergen} sensitization $n=117 / 493$

Food sensitization $n=73 / 495$
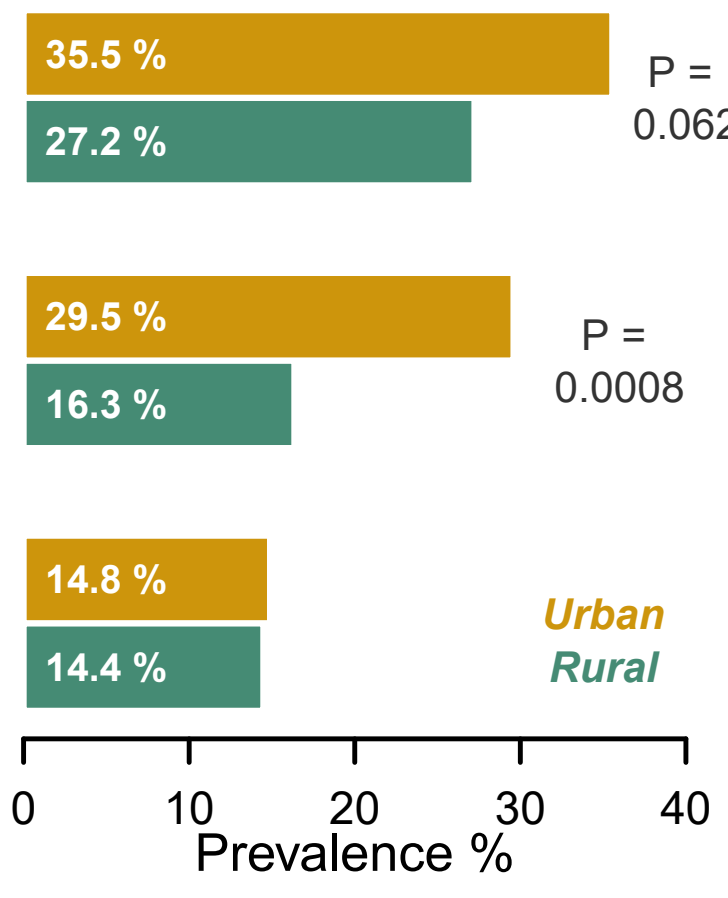

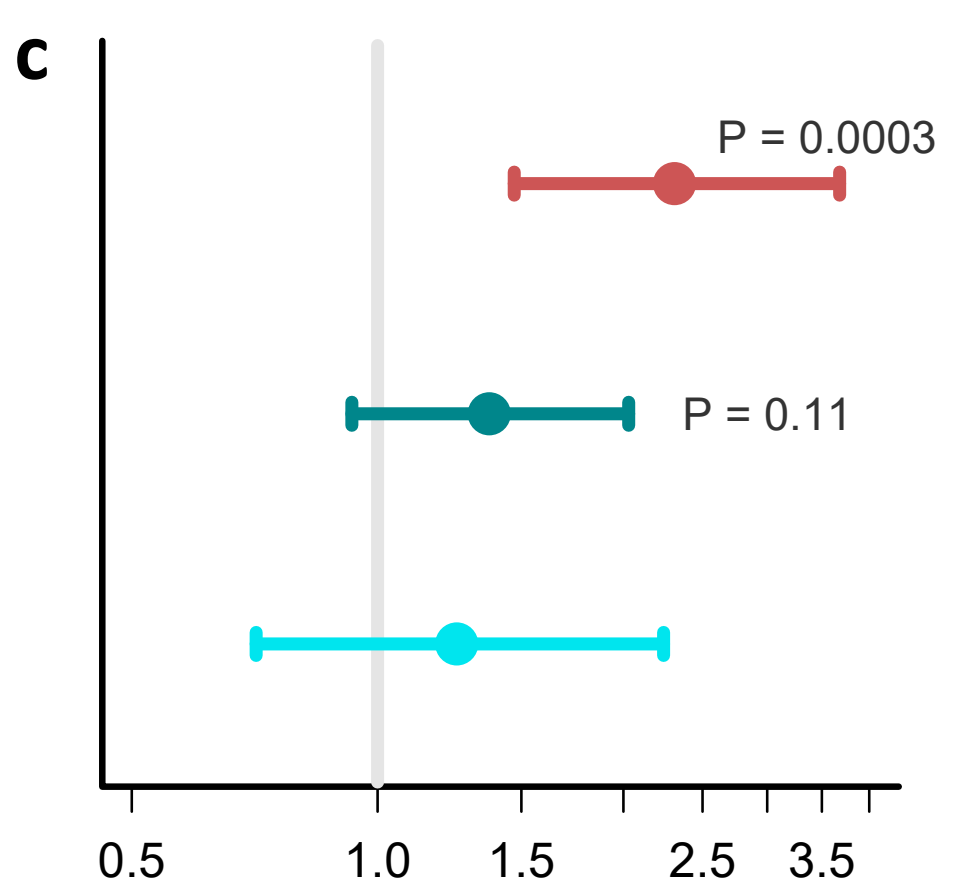

e

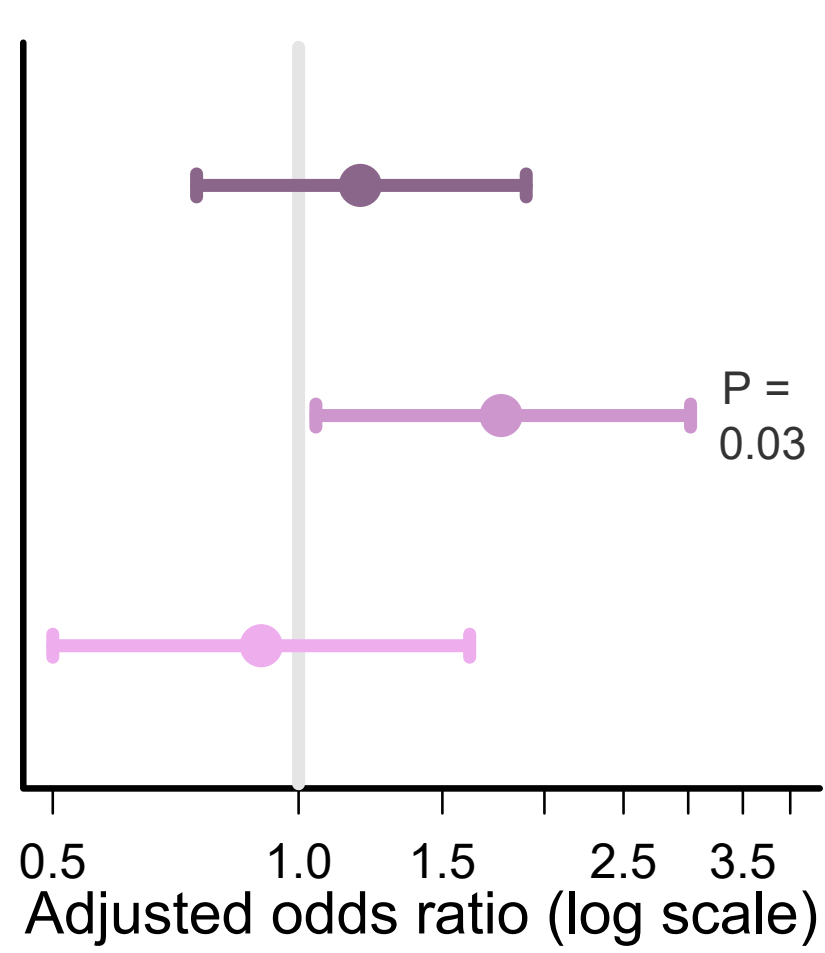





\section{1 week 1 month 3 months}

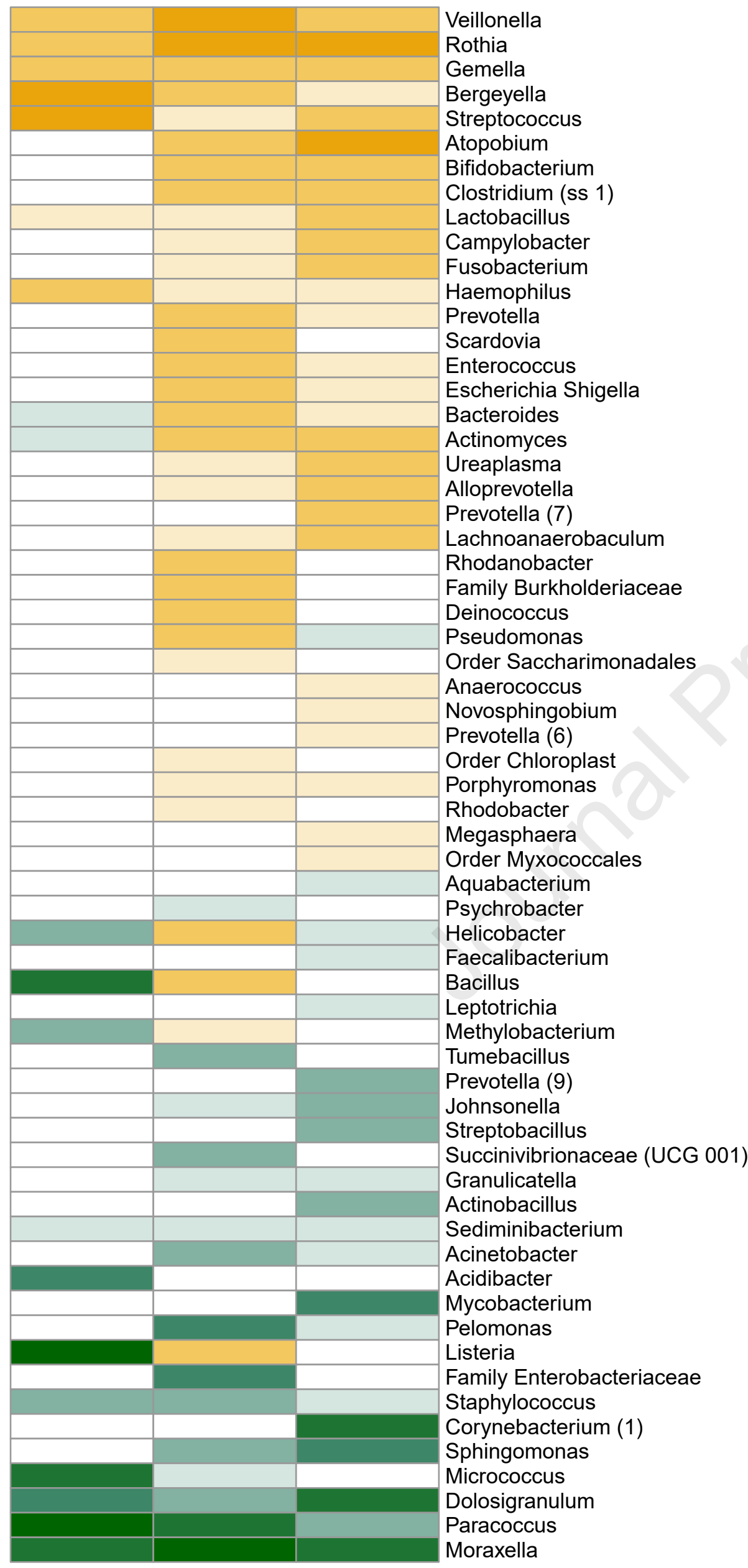

\section{1 week 1 month 1 year}

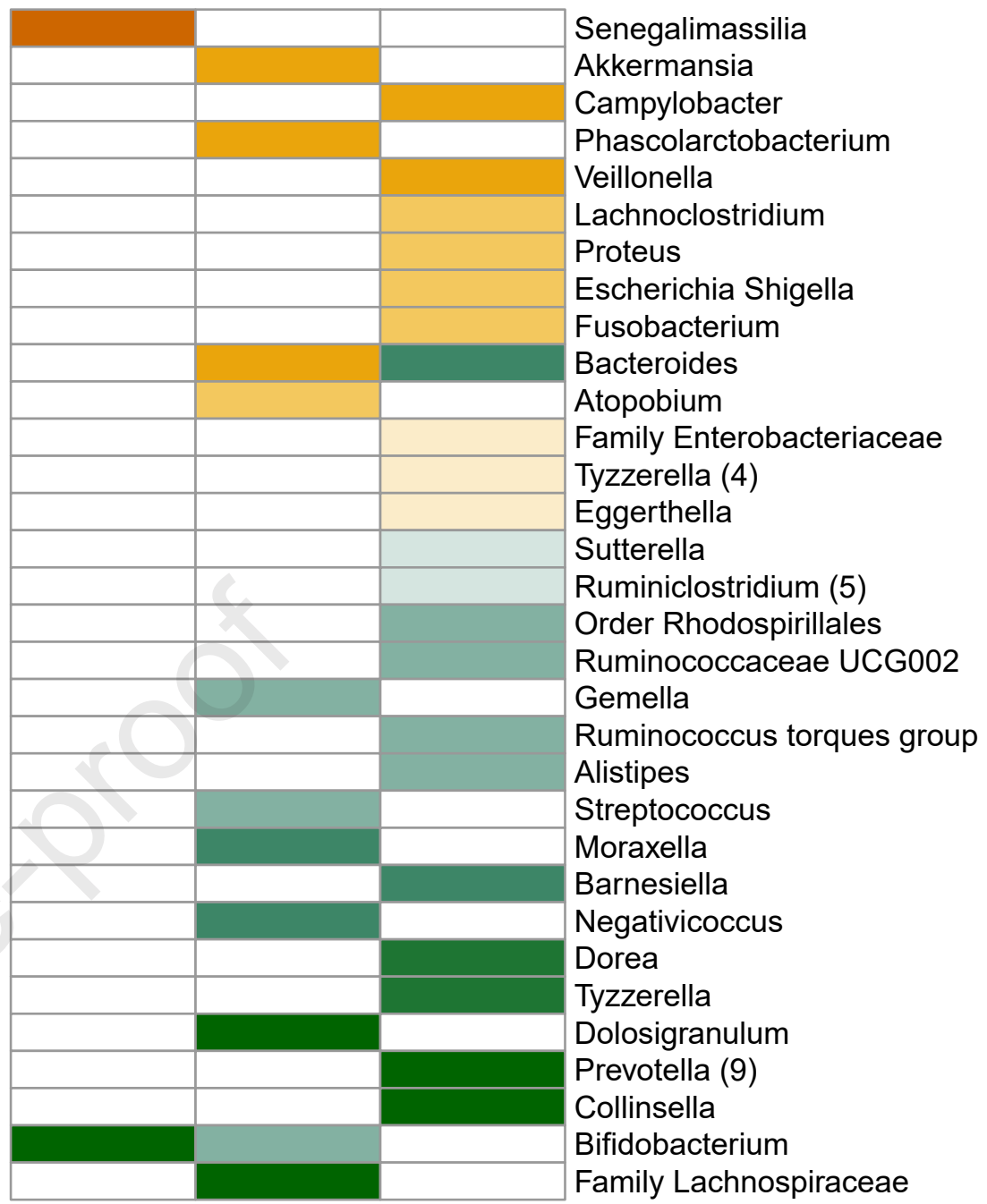

$\mathrm{R} 2=0.020 \quad \mathrm{R} 2=0.028 \quad \mathrm{R} 2=0.057$

$\mathrm{P}=0.0004 \quad \mathrm{P}=1.01 \mathrm{e}-07 \quad \mathrm{P}=1.61 \mathrm{e}-10$

$\begin{array}{lll}\mathrm{R} 2=0.038 & \mathrm{R} 2=0.069 & \mathrm{R} 2=0.062 \\ \mathrm{P}=2.35 \mathrm{e}-09 & \mathrm{P}=3.21 \mathrm{e}-14 & \mathrm{P}=1.26 \mathrm{e}-10\end{array}$

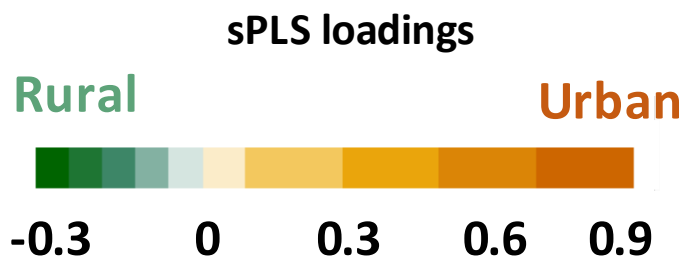


Airway bacterial scores

Asthma

Allergic rhinitis

Eczema

Any sensitization

Aeroallergen sensitization

Food sensitization

Gut bacterial scores

Asthma

Allergic rhinitis

Eczema

Any sensitization

Aeroallergen sensitization

Food sensitization a

b

C $\quad 3$ months

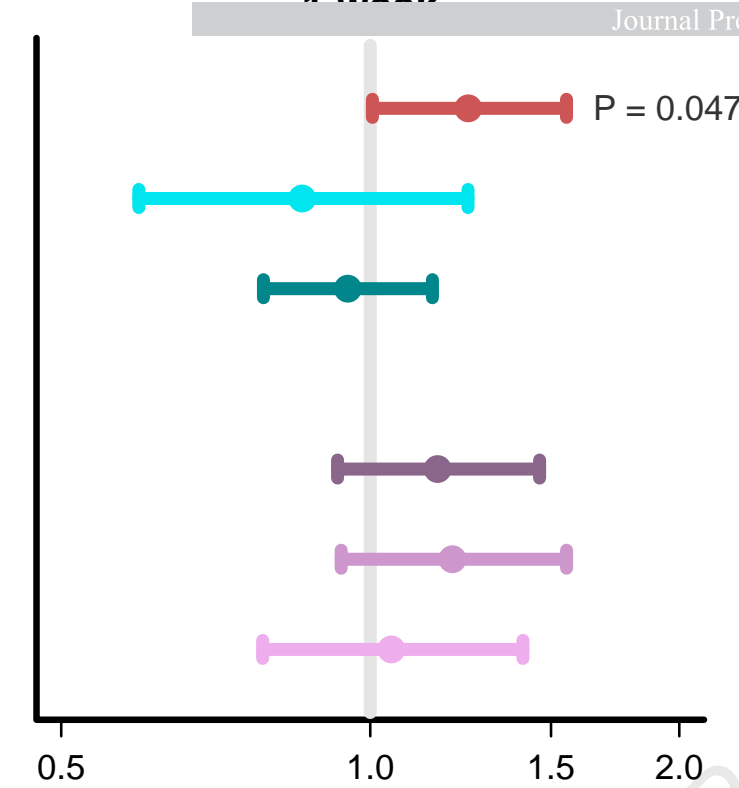

d

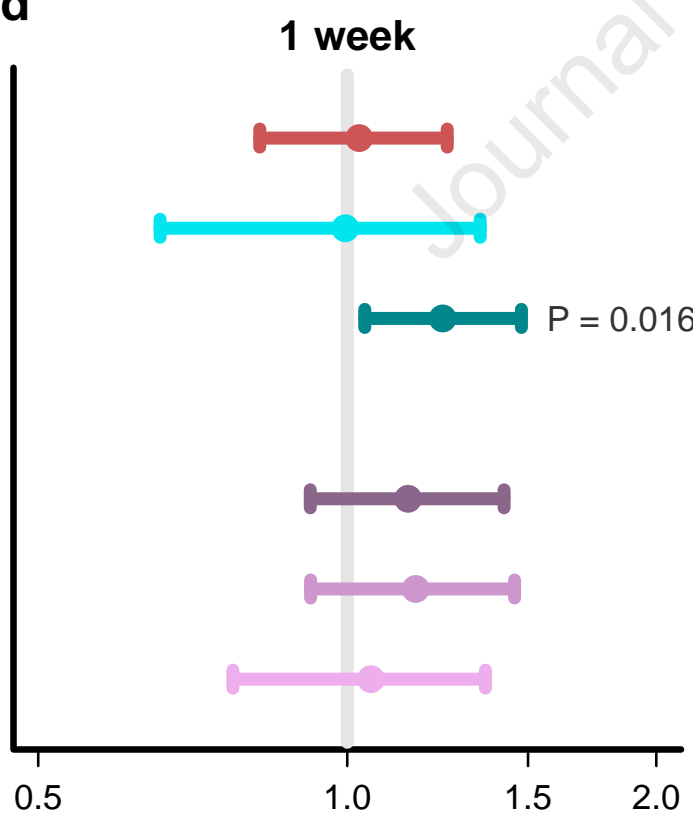

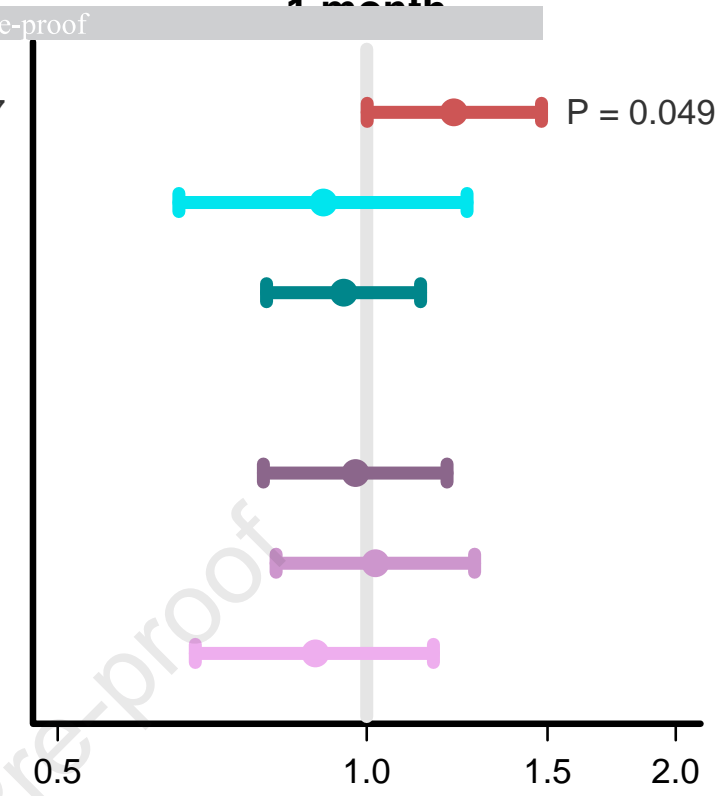

e

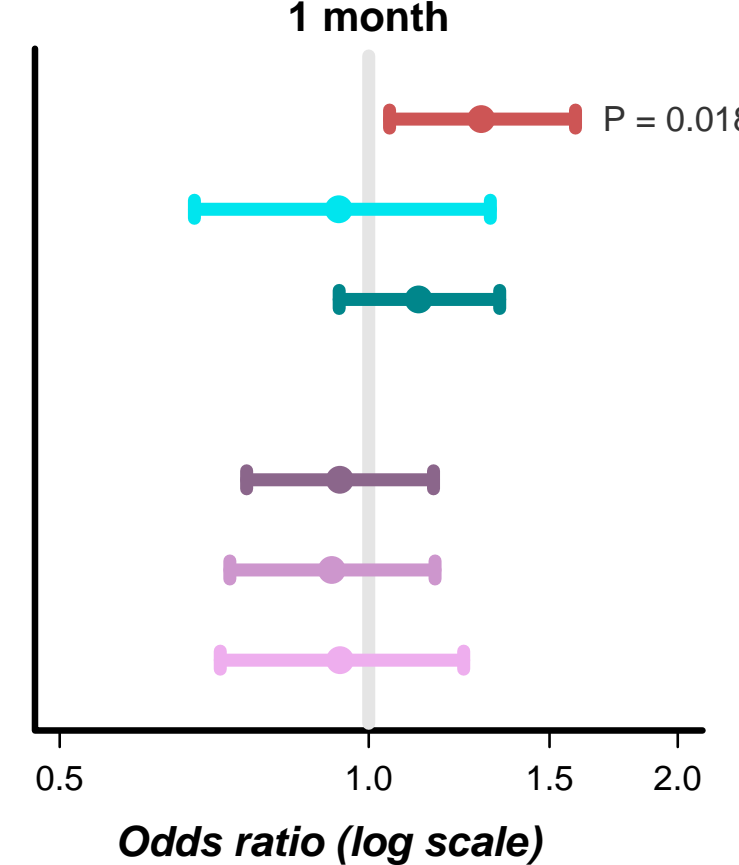

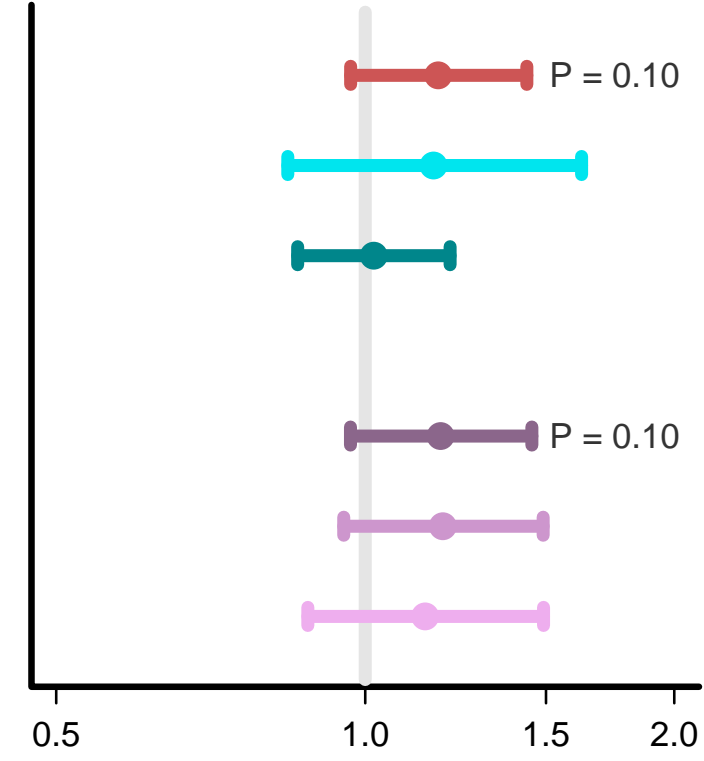

f

1 year

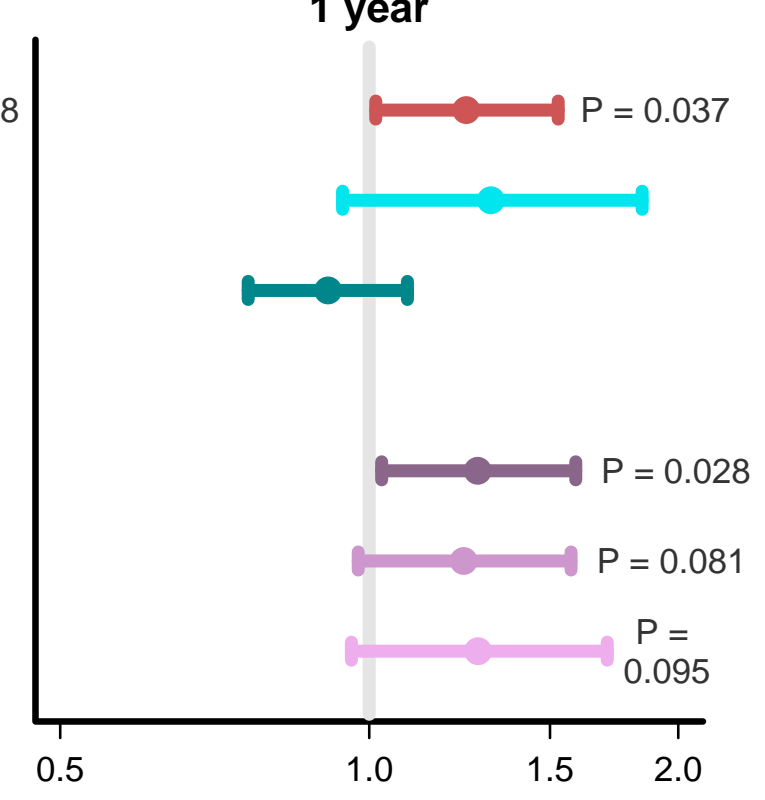




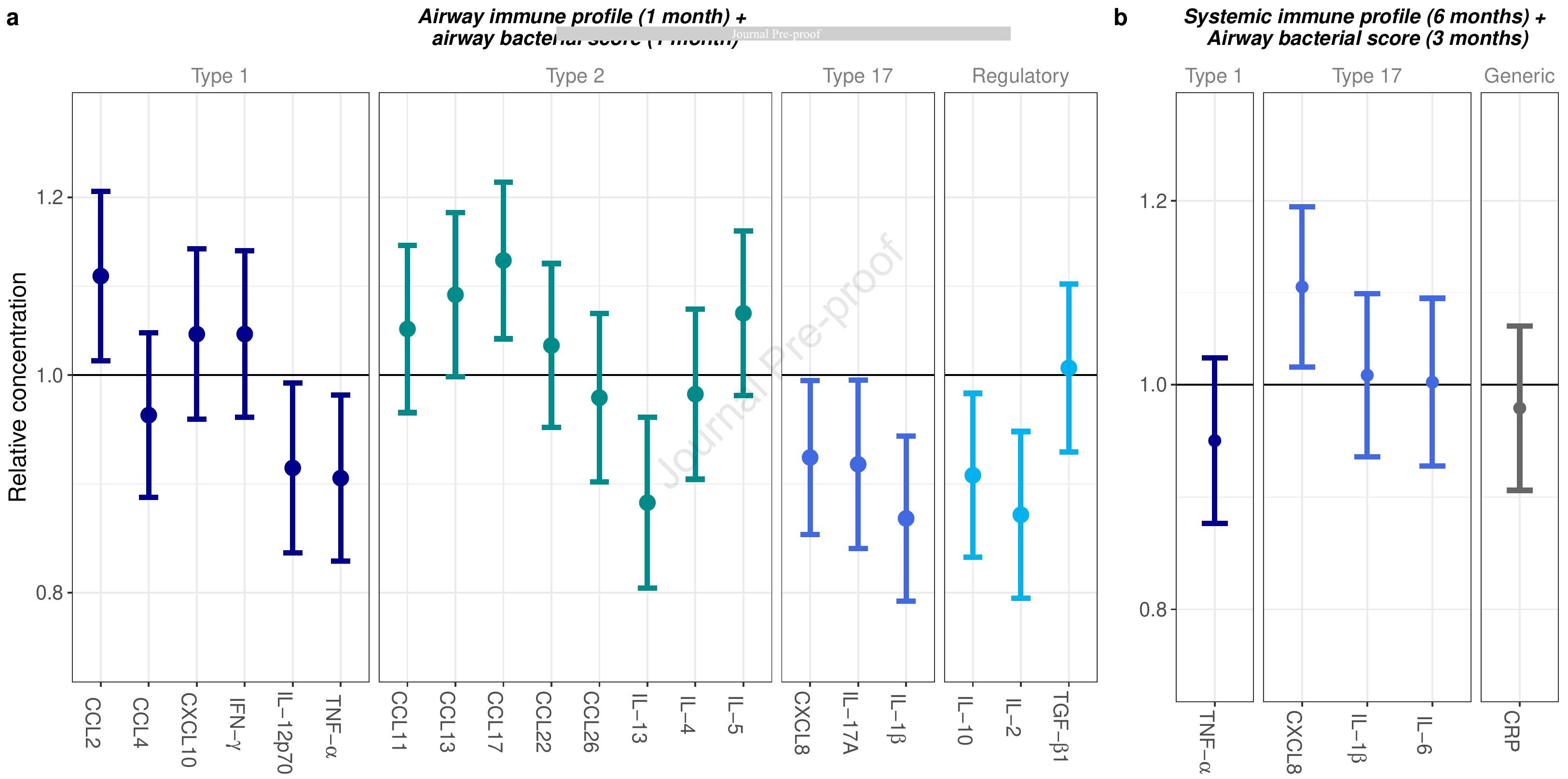



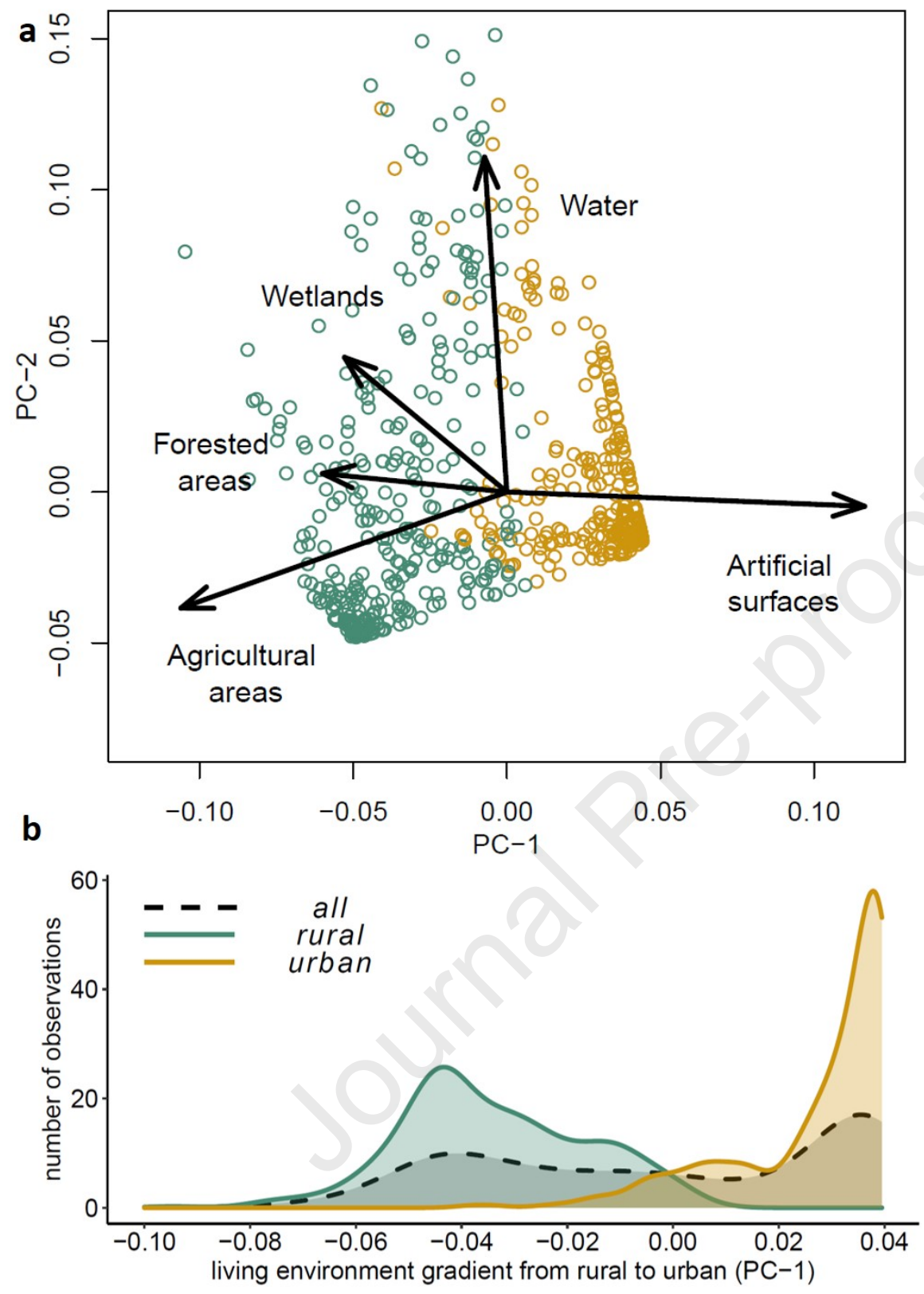
a.

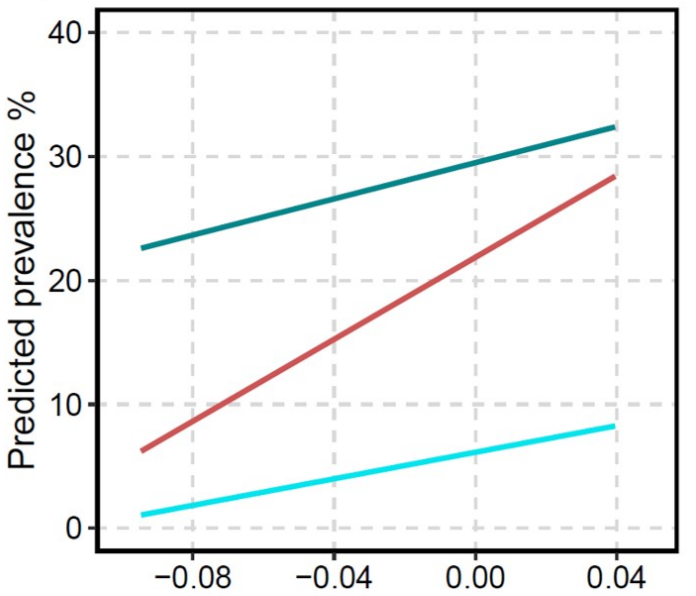

b.

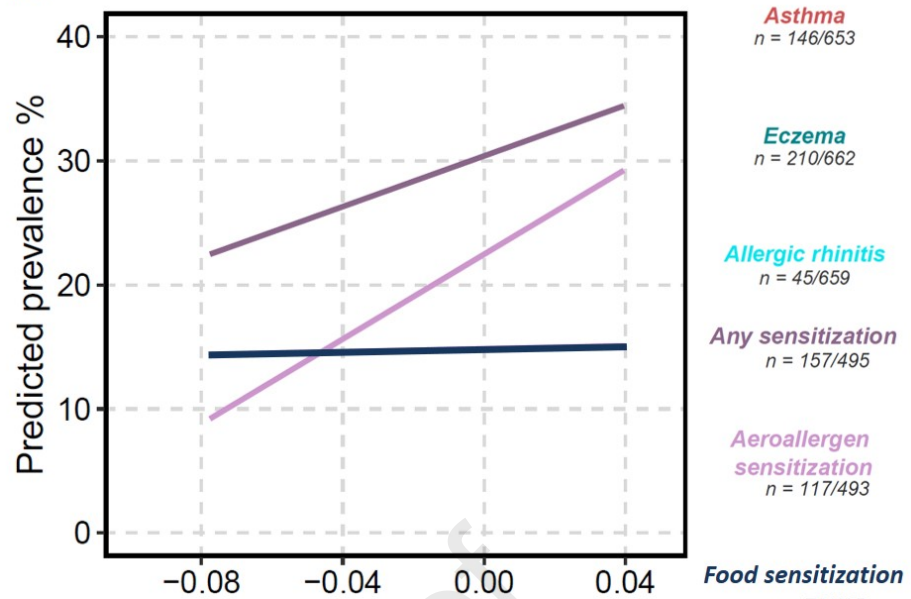

Urbanization gradient 